\title{
Zoology
}

\section{The forelimbs of Octodontidae (Rodentia: Mammalia): substrate use, morphology, and phylogenetic signal \\ --Manuscript Draft--}

\begin{tabular}{|c|c|}
\hline Manuscript Number: & ZOOL-D-20-00092R2 \\
\hline Article Type: & Research Paper \\
\hline Section/Category: & Ecomorphology \\
\hline Keywords: & $\begin{array}{l}\text { Caviomorpha; functional morphology; postcranial indices; skeletal morphology; } \\
\text { substrate preference }\end{array}$ \\
\hline First Author: & M. Julieta Pérez \\
\hline \multirow[t]{2}{*}{ Order of Authors: } & M. Julieta Pérez \\
\hline & GUILLERMO H. CASSINI \\
\hline & $\begin{array}{l}\text { Itati Olivares, Dra. } \\
\text { iolivares@fcnym.unlp.edu.ar }\end{array}$ \\
\hline & $\begin{array}{l}\text { samantha Hopkins } \\
\text { shopkins@uoregon.edu }\end{array}$ \\
\hline & $\begin{array}{l}\text { Marcos Ercoli, Dr } \\
\text { marcosdarioercoli@hotmail.com }\end{array}$ \\
\hline \multirow[t]{3}{*}{ Opposed Reviewers: } & $\begin{array}{l}\text { david Flores } \\
\text { davflor@gmail.com } \\
\text { Professional and personal problems with one of the authors }\end{array}$ \\
\hline & $\begin{array}{l}\text { Virginia Abdala, dra } \\
\text { virginia@webmail.unt.edu.ar } \\
\text { Professional and personal problems with one of the authors }\end{array}$ \\
\hline & $\begin{array}{l}\text { Norberto Giannini } \\
\text { norberto.giannini@gmail.com } \\
\text { Professional and personal problems with one of the authors }\end{array}$ \\
\hline
\end{tabular}


Maria Jose Tulli

majotulli@gmail.com

conflict of interest

Response to Reviewers:

Dear Dr. Thomas C. G. Bosch,

Thank you very much for the comments and suggestions in the manuscript ZOOL-D-

20-00092. We revised the manuscript accordingly. We accepted all the comments and changes made by the reviewer and the copy editor.

Best regards,

Dra. María Julieta Pérez 
Dear Dr. Thomas C. G. Bosch,

Thank you very much for the comments and suggestions in the manuscript ZOOL-D-20-00092. We revised the manuscript accordingly. We accepted all the comments and changes made by the reviewer and the copy editor.

Best regards,

Dra. María Julieta Pérez 
1) Is the first forelimbs analyses that include all genera of Octodontidae.

2) Forelimbs morphology can be used as indicators of substrate preferences.

3) No strong phylogenetic signal is found in octodontids forelimbs traits. 
1 The forelimbs of Octodontidae (Rodentia: Mammalia): substrate use, morphology, and phylogenetic signal

3

4 M. Julieta Pérez ${ }^{\mathrm{a}, \mathrm{b}}$, Guillermo H. Cassini ${ }^{\mathrm{a}, \mathrm{c}}$ and M. Mónica Díaz ${ }^{\text {a, b, d }}$

$5 \quad{ }^{a}$ Consejo Nacional de Investigaciones Científicas y Técnicas - (CONICET)

$6 \quad$ b Programa de Investigaciones de Biodiversidad Argentina (PIDBA), Programa de

7 Conservación de los Murciélagos de Argentina (PCMA)- Facultad de Ciencias Naturales e

8 Instituto Miguel Lillo (IML), Universidad Nacional de Tucumán. Miguel Lillo 251, (4000),

9 Tucumán, Argentina.

10 c División Mastozoología, Museo Argentino de Ciencias Naturales, "Bernardino

11 Rivadavia”, Avenida Ángel Gallardo 470.

12 Departamento de Ciencias Básicas, Universidad Nacional de Luján, Ruta 5 y Av.

13 Constitución s/n, Luján (6700), Buenos Aires, Argentina.

d Fundación Miguel Lillo. Miguel Lillo 205, (4000). Tucumán, Argentina, Sección

San Miguel de Tucumán (4000), Tucumán, Argentina.

17 


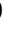

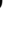

Formatted: Highlight taxonomic richness group (six genera and 14 species) but have great ecomorphological diversity with epigean, semi-fossorial, fossorial, and subterranean forms. We analyzed morphometric variation in humerus and ulna, the possible relationship with substrate preference use, and the presence of a phylogenetic signal in the forelimbs traits (five biomechanical indices). Our results show that, in octodontids, the forelimb variation was not primarily associated with their phylogeny and some attributes are highly explanatory in terms of function, with a clear differentiation between the substrate use gradient extremes (i.e. epigean and subterranean forms). The two forelimb traits, the development of humeral epicondyles and the olecranon process of the ulna, indicative of adaptive trends found in

Octodontidae are consistent with most of those described for other mammals and corroborate the relevance of forelimb characters to differentiate modes of locomotion or substrate preferences.

Key words: Caviomorpha, functional morphology, postcranial indices, skeletal morphology, substrate preference.

7 


\section{Introduction}

Caviomorph rodents constitute one of the richest and most diverse groups of South

American mammals, they reached the continent during the middle Eocene and diversified via geographic isolation during part of the Cenozoic (Vucetich et al., 2015). Among them, Octodontidae is a family of small rodents (100 $\mathrm{g}$ in Octomys to $300 \mathrm{~g}$ in Octodon), restricted to southern South America, between $15^{\circ}$ to $43^{\circ} \mathrm{S}$ latitude (Reig, 1989; Gallardo et al., 2007; Ojeda et al., 2013; Verzi et al., 2015). They are distributed in Argentina, Bolivia, and Chile in a wide diversity of habitats including mesic to arid open land biomes, in the Andean region or adjacent lowlands (Gallardo et al., 2007). Although their taxonomic richness is low (six genera and 14 species), they show a great ecomorphological diversity (Mares and Ojeda, 1982; Contreras et al., 1987; Lessa et al., 2008; Ojeda et al., 2013; Verzi et al., 2015).

In the octodontid rodents, four substrate preferences, are recorded based on their behavior: epigean, semi-fossorial, fossorial or semi-subterranean, and subterranean (see section 2 Material and Methods). Epigean forms include the mountain degu (Octodontomys gliroides, body mass 100-200 g) and the long-tailed octodon (Octomys mimax, mean body mass $96 \mathrm{~g}$ ) that inhabit rocky desert and semi-desert environments (Sobrero et al., 2010; Verzi et al., 2015; Pérez and Díaz, 2018; Campos, 2019; Rivera and Qüense, 2019). O. gliroides also lives in small burrows among rocks or cactus roots (Pérez and Díaz, 2018). As for the most species, information on the ecology of $O$. mimax is scarce-er null, but its distribution seems restricted to areas with rocky slopes and ravines (Sobrero et al., 2010). Semi-fossorial forms are represented by the species of the genus Tympanoctomys, endemic to central western Argentina, which inhabit in desert scrubland, dunes, and salty plains (Mares et al., 2000; Ojeda et al., 2013) in complex burrows. These are small-sized 
octodontids, with body mass 67-104 g (Verzi et al., 2015). Fossorial or semi-subterranean forms include the species of the genera Aconaemys (meanbody mass of males $118.9 \mathrm{~g}$ ) and Octodon (meanbody mass $200 \mathrm{~g}$ one of the biggest octodontid), which primarily inhabits the Valdivian temperate forest and Patagonian steppe (Verzi et al., 2015; Tammone, 2019; Sobrero and Tammone, 2019). Subterranean forms only include the coruro (Spalacopus cyanus), a colonial endemic species from to central Chilenian valley that lives in a single burrow system, and feeds underground with body mass 80-120 g (Torres-Mura and Contreras, 1998; Verzi et al., 2015).

Despite this variability, the digging capability is prevalent in Octodontidae as well as in its sister family, Ctenomyidae (Lessa et al., 2008). The development of adaptations to burrowing in cranial and the appendicular skeleton was extensively studied in the Ctenomyidae, but not in Octodontidae (Verzi et al., 2002; Morgan and Verzi, 2006; Verzi and Olivares, 2006; Lessa et al., 2008; Morgan and Verzi, 2011; Morgan et al., 2017; Pérez et al., 2017). Previous studies show that octodontid and ctenomyid rodents dig with both claws (scratch-digging) and incisors (chisel tooth-digging) (Vassallo, 1998; Stein, 2000). Since the late 1980 s, the postcranial skeleton has been successfully used in morphofunctional analysis to examine the locomotor apparatus in mammals (e.g. Hildebrand, 1985; Van Valkenburgh, 1987; Lewis, 1997; Argot, 2001, 2002, 2003; Candela and Picasso, 2008; Flores, 2009; Flores and Díaz, 2009; Hopkins and Davis, 2009; Toledo et al., 2012; Samuels et al., 2013; Chen and Wilson, 2015; Verde Arregoitia et al., 2016; Moore et al., 2017; Hedrick et al., 2020; Toledo et al., 2020). The application of Radinsky's (1987) form-function correlation paradigm is considered by many evolutionary biologists as an important tool for reconstructing ecology from ancient or recently extinct organisms, as well as rare, shy or scarce extant taxa (Hopkins and Davis, 2009; Vizcaíno and Bargo,
Formatted: Highlight 
2019). The interaction between an organism and its environment through substrate preference (the type of substrate where it lives and performs its activities) and substrate use (how they interact with one or more types of substrates such as locomotion, shelter, and food attainment), together with body mass and feeding behavior, constitutes a basic biological attribute to characterize extinct vertebrate life habits (Polly, 2007; Hopkins and Davis, 2009, Vizcaíno et al., 2016). Recent contributions have focused on ecomorphological approaches to correlate limb functional indices with substrate preference and/or use in xenarthrans (Vizcaíno et al., 1999; Vizcaíno and Milne, 2002), carnivores (Jenkins and Camazine, 1977; Van Valkenburgh, 1987), ungulates (Kappelman, 1988; Thomason, 1991), and rodents (Elissamburu and Vizcaíno, 2004; Samuels and Van Valkenburgh, 2008; Elissamburu, 2010; Elissamburu and De Santis, 2011, Morgan et al., 2017). These functional indices represent attributes of bones and the mechanical efficiency of principal muscles related to limb function (Howell, 1944; Hildebrand and Goslow, 2001; Vizcaíno et al., 2016 and references therein). Among them, the index of fossorial ability (IFA; referred hereafter as OI), developed by Vizcaíno et al. (1999) and inspired on Hildebrand (1985), was extensively examined and has shown a recognizable pattern of increased olecranon length in the most powerful diggers in many mammalian groups. However, its phenotypical expression was constrained by phylogeny. For example, the best diggers among carnivorans and caviomorph rodents have lower values than the less fossorial armadillo, but in each clade, diggers have longer olecranon processes than their non-digging close relatives (Vizcaíno and Bargo, 2019). In some octodontids, such as Octomys and Tympanoctomys, skeletal features, for example, narrow humeral epicondyles and poorly developed olecranon processes, not related with digging capacity are recorded (Lessa et al., 2008; Pérez et al., 2017), and the most subterranean form (Spalacopus) is 
characterized by well-developed olecranon and epicondylar processes (Lessa et al., 2008; Pérez, 2019). However, contrarily to ctenomyids and cricetid sigmodontines, in most octodontid species the postcranial elements adaptations to digging are poorly known, as well as their ecological aspects and form-function relationship (Pérez et al., 2017; Pérez, 2019).

In this study, we aimed to establish if there is a relationship between the forelimb traits and substrate preference use in octodontid rodents within an ecomorphological framework. We used biomechanical indices that have been shown to carry an ecomorphological signal in other taxa to study this aspect in a broad sample of octodontids with burrowing behavior, ranging from epigean to subterranean. We also evaluated the effect of phylogeny in the acquisition of such traits and focused on determining the relative performance of forelimbs traits as predictors of substrate used in these South American rodents.

\section{Materials and Methods}

\subsection{Specimens.}

—We examined 94 adult specimens of all the living genera of the family Octodontidae (the number of specimens in brackets): Aconaemys fuscus (2), A. porteri (20), A. sagei (3), Octodon bridgesi (4), O. degus (1), Octodon sp. (4), Octodontomys gliroides (12), Octomys mimax (3), Spalacopus cyanus (11), Tympanoctomys aureus (17), T. barrerae (14), $T$. kirchnerorum (2), and T. loschalchalerosorum (1). We include specimens with complete and well-preserved forelimbs; the number of individuals represents their availability in the biological collections. In some specimens, only humeri were available: Octodontomys gliroides (6), T. aureus (15), T. barrerae (10) and all specimens of $T$. kirchnerorum, and $T$. 
loschalchalerosorum. All specimens are stored in the mammalogy collections of the following institutions: CMI (Colección de Mamíferos IADIZA, Mendoza, Argentina); CML (Colección Mamíferos Lillo, Universidad Nacional de Tucumán, Tucumán, Argentina); CNP (Colección de Mamíferos “Elio Massoia”, Centro Nacional Patagónico, Puerto Madryn, Chubut, Argentina); MLP (Museo de La Plata, La Plata, Buenos Aires, Argentina); and UACH (Universidad Austral de Chile, Valdivia, Chile). In addition, we included some specimens of Octodon collected in Argentina, treated in our analyzes as Octodon sp. (Verzi et al., 2014; 2015). For the specific localities and collection numbers of specimens see Appendix I.

\subsection{Substrate preference categories.}

- The substrate preferences were classified, according to Polly (2007), Samuels and Van Valkenburgh (2008), Fabre et al. (2015), and Verde Arregoitia et al. (2016), as follows: (1) epigean, which includes those species that may dig to modify or make a burrow (but not extensively) like Octodontomys gliroides and Octomys mimax; (2) semi-fossorial, characterized by non-subterranean diggers, which regularly digs to build burrows for shelter, but not to forage which included the species of Tympanoctomys; (3) fossorial, characterized by diggers which regularly dig to build extensive burrows as shelter or for foraging underground, which included the species of the genera Aconaemys and Octodon; and (4) subterranean, characterized by species dwelling fully underground like Spalacopus cyanus.

\subsection{Morphological variables and biomechanical indices.}

—Based on previous studies (Biknevicius, 1993; Elissamburu and Vizcaíno, 2004; Morgan and Verzi, 2006; Hopkins and Davis, 2009; Elissamburu and De Santis, 2011), seven measurements from humeri and ulnae were taken with digital calipers to the nearest 0.01 
mm (Fig. 1). These measurements correspond to diameters and functional lengths (length between articular surfaces) of the bones and muscular insertion sites. Five indices with functional significance, calculated from linear measurements, were selected, based on a qualitative assessment and previous proposals (Biknevicius, 1993; Vizcaíno et al., 1999; Fernández et al., 2000; Elissamburu and Vizcaíno, 2004; Morgan and Verzi, 2006; Elissamburu, 2010; Elissamburu and De Santis, 2011). These indices were: 1) Shoulder moment index (SMI): DLH/FHL x 100, where DLH is the deltoid length of the humerus and FHL is the functional length of the humerus; this index is an indication of the mechanical advantage of the posterior deltoid muscle acting across the shoulder joint; 2) Epicondylar index (EI): DEH/FHL x 100, where DEH is the epicondylar width of the humerus; this index depicts the proportional width of the distal epiphysis that describes indirectly the available space for hand and digit flexor muscles; 3) Humeral robustness index (HRI): APDH/FHL x 100, where APDH is the anteroposterior diameter of the humerus; this index allows visualizing the proportion between the width and length, giving an idea of their comparative slenderness or robustness, indirectly, their potential compliance to facing mechanical loads; it also reflects the amount of available space for musculature; 4) Ulnar robustness index (URI): TDU/FUL x 100, where TDU is the transverse diameter of the ulna, and FUL is the functional ulna length; in addition to describing the relative robustness of the ulnar diaphysis, this index describes the available space for zeugopodium pronator-supinator muscles, as well as, hand flexor musculature and 5) Olecranon index (OI): OL/(FUL-OL) x 100, where OL is the length of the olecranon process; this index gives a measure of the mechanical advantage of the $m$. triceps and dorso-epitrochlearis for forearm extension as the ratio between in-lever (ulnar olecranon 
process) and out-lever (represented by the rest of the ulna) arms. Descriptive statistics (e.g., mean, standard deviation) were calculated using the R 3.6.1 software (R Core Team, 2019).

\subsection{Phylogenetic signal.}

- To analyze putative phylogenetic biases in the biomechanical indices, we perform two analyses on the phylogenetic tree from Suárez-Villota et al. (2016). The first, an orthonormal decomposition of variance (Ollier et al., 2006), which consists of an orthonormal transformation on a matrix obtained from the topology of the tree, to construct a new mathematical structure function called an orthogram by computing vectors (orthobases) that describe the topology of the tree without relying on estimated branch lengths and diversification times. In this analysis, four statistical parameters were applied to evaluate the phylogenetic dependence of a given trait and whether it is concentrated in one or more particular nodes of a tree that includes the taxa under study. In the second analysis, $K$-statistics was calculated (Bloomberg et al., 2003) for all continuous variables using Kcalc of R package picante v. 1.7 (Kembell et al., 2018). The $K$-statistic is a ratio between observed and expected proportions between mean squared errors of raw versus phylogenetically transformed data from the phylogenetic mean. It was designed to quantify the degree of phylogenetic signals regardless of the tree size (Bloomberg et al., 2003). A $K$ value of 0 indicates the absence of phylogenetic bias, whereas 1 suggests following the Brownian motion or neutral model of character evolution, and values above 1 indicate high bias and suggest following the Ornstein-Uhlenbeck or one-dimensional random walk with a central tendency (i.e., a stabilizing force) of character evolution (Bloomberg et al., 2003).

\subsection{Allometry.}

- The relationship between the raw measurements and the indices with size were calculated using standardized major axis (SMA) regression in the smatr package (Warton et 
al., 2006) for R software. The geometric mean (GM), derived from the $n^{\text {th }}$ root of the product of $n$ measurements was used as a size proxy (Samuels and Van Valkenburgh, 2008). In these analyses, variables were log-10 transformed and species mean was used in order to evaluate the interspecific allometry (evolutionary scaling; Klingenberg and Zimmermann, 1992). Deviations from isometry were assessed by comparing the allometric coefficient with the value of 1 expected under geometric similarity by means of $F$-tests (Warton and Weber, 2002).

\subsection{Multivariate morphometric variation.}

-Principal Components Analysis (PCA) was used for identifying the main sources of variation in the forelimb indices. As indices were influenced by allometric scaling (see results), we analyzed the size-independent PCAs using the correlation matrix, after the $\log 10$-transformation of the indices standardized by the base 10 log-transformed GM (Strauss, 2010). Meaningful PCs were assessed by using the broken stick method as implemented in the vegan 2.5-3 R package (Oksanen et al., 2018). The morphological ranges that each group occupies in the morphospace were compared as a hypervolume of the convex hull that minimally encloses the data. In addition, the overlap of these hypervolumetric groupings in morphospace was evaluated using two parameters the Jaccard and Sørensen similarity indices from the hypervolume 2.0.12 R package (Blonder and Harris, 2019).

Phylogenetic Flexible Discriminant Analysis (pFDA), which accounts for phylogenetic covariance when predicting group membership, was performed on the data set. This analysis developed by Motani and Schmitz (2011) is based on the protocols by Hastie et al. (1994) and combined with a phylogenetic GLS regression (Martins and Hansen, 1997) under R environment (R Core team 2019). In this analysis, the lambda of 
Pagel (1999) needed to be defined. We use the function optLambda from Motani and Schmitz (2011) to identify the optimal lambda, i.e., where is the strongest correlation between morphology (variables or indices) and ecology (substrate preference categories). A lambda close to one does not modify the tree and the models equal to Brownian motion, a lambda of zero results in the tree turning into a star phylogeny, which is equivalent to an independent model. The analyses were carried out with function phylo.fda from phylo.fda.v0.2.R scripting in Motani and Schmitz (2011) on two data sets: (1) the whole sample with three biomechanical indices (SMI, HRI, and EI; only humeri) and (2) the five biomechanical indices excluding the specimens with missing data (see above). This accounts for both, the influence of a more inclusive taxon sampling and the element considered (humeri and ulnae). Additionally, as a comparative framework, we conduct a Discriminant Analysis (DA) on these two data sets (for detailed procedure see supplementary material 1 in the supplementary online Appendix).

\section{Results}

\subsection{Indices.}

—In Table 1, descriptive statistical parameters for all indices by species are summarized. Among the rock rats (genus Aconaemys), A. fuscus showed the highest values for shoulder moment index (SMI) also compared to all other species, and the olecranon index (OI), while A. sagei had the highest epicondylar development in the humerus (EI), as well as the most robust humerus (HRI) and ulna (URI). In the degus (genus Octodon), O. bridgesi had the highest SMI and EI, while O. degus exhibited high URI and highest OI. Among vizcacha rat species (genus Tympanoctomys), T. aureus exhibited the highest values almost for all the calculated indices (unknown URI and OI for T. kirchnerorum and $T$. 
loschalchalerosorum), sharing the same EI value than T. barrerae. The mountain degu, Octodontomys gliroides, had the highest HRI compared to all species considered here, while Octomys mimax showed the lowest URI. Finally, the coruro (Spalacopus cyanus) had the highest EI and OI compared to all studied species (see also supplementary material 2).

\subsection{Phylogenetic signal.}

—The results of the orthonormal decomposition of variance for all biomechanical indices of the forelimb, except the epicondylar index (EI), showed that none of the four statistics rejected the null hypothesis of a uniform distribution of orthogram values. Only in EI, the Dmax was significantly different from the null hypothesis (Table 2). Moreover, all index values of the cumulative orthogram remained within the confidence envelopes, but in EI some nodes showed values beyond the confidence interval (supplementary material 3). Additionally, the calculation of the $K$ statistic, with its respective $p$-value, for each index, only yielded a significant phylogenetic signal for two of them, the EI and OI (Table 2).

\subsection{Allometry.}

-All regressions were significant except for HRI (Table 3). Most regressions resulted in small determination coefficients values (i.e. $<0.50$ ), and only DLH among measurements and OI among indices showed high values (i.e. $>0.70$, Table 3 ). The log-10 transformed humeral lengths (FHL and DLH) did not differ from isometry, while the diameters and all ulnar dimensions showed positive allometry. Among the indices, SMI resulted in negative allometry and the rest of the indices (except HRI) showed strong positive allometry (Table $3)$.

\subsection{Multivariate morphometric variation.}

-In the PCA results, the two first PCs accounted for more than $81 \%$ of the total sample variation. The broken stick assessment showed that only these two PCs were significant. 
On the one hand, the variable loadings of PC1 (52\%) showed that negative values have a strong association with the HRI (-0.73), while toward positive values they correlate with OI (0.55) and to a lesser degree with EI (0.34) (Table 4). On the other hand, PC2 (29\%) negative values were weakly related to almost all indices (about -0.21) but URI (0.88) was strongly associated with positive values. The morphospace depicted by these two components gathered O. mimax, Octodon sp., O. gliroides, T. aureus, and T. barrerae on the left side of PC1 (high HRI), while A. fuscus, A. porteri, A. sagei, O. degus, and S. cyanus were located on the right side (high OI and EI) (Fig. 2A). This arrangement also showed that all species of Aconaemys were very close to one another around the origin. On PC2 the octodontids with a lower URI lay towards negative values. Octodon showed a gradient in this axis with $O$. degus in the upper side (highest URI), Octodon sp. in the middle, and $O$. bridgesi at the bottom with the lowest URI. The PC1 displayed a gradient from epigean (negative extreme) to subterranean species (positive extreme; Fig. 2B). The fossorial taxa formed a large cloud (i.e., highest morphological disparity) with their centroid close to the origin. While the semi-fossorial taxa seem to be included in the left fossorial morphospace (hypervolume package tests: Jaccard similarity $=0.44$ and Sørensen similarity $=0.61$, the epigean partially overlapped with both of them (hypervolume package tests: Jaccard similarity $=0.308$ and 0.538 ; Sørensen similarity $=0.471$ and 0.699 with fossorial and semifossorial respectively). The subterranean morphospace is the only group with virtually no overlap (all hypervolume package tests equal zero except for fossorial: Jaccard similarity $=0.103$ and Sørensen similarity $=0.187)$. The PC2 showed no functional or taxonomic pattern.

The Phylogenetic Flexible Discriminant Analysis (pFDA) performed in the whole sample using three biomechanical indices (SMI, HRI, and EI) is shown on supplementary 
material 4 in the supplementary online Appendix. When the five indices were included (where two species T. kirchnerorum and T. loschalchalerosorum with missing data were removed), the estimated optimal lambda of Pagel was 0.23 , and the confusion matrix showed that the two epigean species and the subterranean one were correctly classified. The categories fossorial and semifossorial presented high misclassifications: two of the five fossorials species (Aconaemys fuscus and A. porteri) were classified as semifossorial species (60\%) and one of the two semifossorial species (Tympanoctomys aureus) was misclassified as fossorial form. Some misclassifications appeared when evaluating the reclassification at increasing lambda values. Among fossorials forms, Octodon degus was misclassified as semifossorial from lambda 0.4 to 1 , and Aconaemys fuscus and O. bridgesi from 0.8 to 1 , and among semi-fossorials only Tympanoctomys aureus was misclassified as epigeous at lambda from 0.8 to 1 (Fig. 3).

\section{Discussion}

The phylogenetic study we used for our comparative methods was also an analysis where all octodontid genera and most of their species were included. The data are consistent with observations made by other authors for some members of the family Octodontidae (Lessa et al., 2008), and provide new information for species poorly known or recently described. For example, A. porteri, A. sagei, and O. bridgesi are included for the first time in this type of analysis, giving us a perspective of the structure of the forelimbs through the morphological proxies. The specimens of Octodon sp. included here are characterized by higher values of humeral robustness and the lowest olecranon index compared with those of $O$. bridgesi and O.degus. It is important to mention that few specimens of Octodon were included in this study, which limits the conclusions. For this reason, the specimens 
preserved in museum collections are valuable records, not only for taxonomic or phylogenetic studies, but also in the development of studies on different disciplines, e.g., ecomorphology and ecology (Verde Arregoitia et al., 2016), and all the data generated here support it.

The octodontid and ctenomyid rodents, two closely related families, were included within the five extant families of rodents in which the fossorial and subterranean habits have evolved independently, as a further specialization in close association with the emergence of open environments during mid to late Cenozoic (Lessa et al., 2008; Álvarez et al., 2020). This adaptation is especially interesting and encourages further studies about the behavioral and structural adaptations in octodontid rodents. Lessa et al. (2008) analyzed and compared the musculoskeletal characteristics in some octodontids, and concluded that neither Octomys mimax nor Tympanoctomys barrerae shows great skeletal adaptations related to digging capacity. We agree with this proposal adding T. aureus to this condition. In $T$. aureus, the construction of tunnels, almost parallel to the ground surface, was observed (M.M. Díaz and R.M. Barquez personal observations), and as in Octodon and Aconaemys, the tunnels consist in complex burrows with several branches and openings (Lessa et al., 2008).

The significant biomechanical forelimb variation found in octodontids was not primarily associated with their phylogeny. It is noteworthy that phylogenetic flexible discriminant analyses showed an optimal lambda of Pagel of zero (expected under the complete absence of phylogenetic signal), and that most misclassification cases started at high lambda values (e.g. 0.8) except for Octodon degus. Furthermore, some morphological traits could be associated with particular habits and therefore understood as specializations. It is noteworthy that in caviomorph rodents, using craniomandibular information has shown 
a significant phylogenetic signal (Álvarez, 2012; Álvarez et al., 2020). This seems to be a general pattern in mammals, as some structures as limbs and mandibles reflect functions better than the cranium, which could have experienced different selective pressures (see Caumul and Polly, 2005; Cardini and Elton 2008; Cassini 2013; Vizcaíno et al. 2016). We found low phylogenetic signals for two of the morphological and ecological traits in the forelimb (EI and OI) in accordance with $K$-values, and following the method of Ollier et al. (2006). The pattern found in our analysis corresponded to a diffuse phylogenetic dependency in EI, and absence of phylogenetic dependence for the remaining indices (supplementary material 3 in the supplementary online Appendix). Moreover, in the phylogenetic and non-phylogenetic discriminant analyses, no significant differences were recorded. For the olecranon index (IFA sensu Vizcaíno et al., 1999), we found a pattern in most octodontid diggers, evidenced by an increase in olecranon length, as was demonstrated among other scratch digging mammals (see Vizcaíno and Bargo, 2019 and references therein). Among members of Octodontidae, it could be interpreted as this ulna attribute is highly explanatory in terms of function and probably less useful in a phylogenetic frame.

The Epicondilar Index proved to be one of the variables that most contributed to the discriminant functions. This could explain, in part, the high correspondence between the whole sample (with only three indices SMI, HRI, and EI) and the partial sample (with the five indices). As in many mammals, the scratch-digging behavior is evidenced by the production of large forces by the forelimbs. Consequently, shortening of the forelimb (reducing out-lever) and enlargement of muscular attachments (increasing both in-lever and the area of insertion) occur in order to improve mechanical advantage for muscles involved in digging (e.g., hand flexor musculature; see Hildebrand, 1985; Stein, 2000; Polly, 2007; 
Samuels and Van Valkenburgh, 2008, Vizcaíno et al., 2016). Some authors have studied the forelimb and hindlimb adaptations, especially the digging capacity of Ctenomys (family Ctenomyidae), and concluded that the greater development of the medial epicondyle could be an early specialization for digging (Elissamburu and Vizcaíno, 2004; Morgan and Verzi, 2006; Lessa et al., 2008; Elissamburu and De Santis, 2011; Morgan and Álvarez, 2013; Morgan et al., 2017; Vassallo et al., 2019). Also, this represents one of the main characters by which to recognize the digging fossorial forms. Accordingly, the subterranean Spalacopus exhibits enlarged muscle attachments in epicondyles of the humerus and olecranon process of the ulna (Epicondyle and Olecranon indices; Fig. 4E). Similar traits are observed in Aconaemys and Octodon (fossorials), plus the greater mechanical advantages of the deltoid and pectoral muscles, due to the pronounced attachment sites for these musculatures (deltoid crest; Fig. 4), and among octodontids the deltoid crest shows a variation in its development plus a variation in the orientation (anterior or more lateral; Fig. 4). Similarly, a robust ulna may be related to the development of several muscles of the forearm and manus, such as pronators, supinators, and deep digital flexors muscles. These are associated with the major musculoskeletal modifications of scratch-diggers with increased strength in flexing the larger digits and the wrist (Hildebrand, 1985). Conversely, evident specializations in the forelimb are not observed and are probably not necessary in epigeous taxa such as $O$. gliroides and $O$. mimax. Accordingly, they exhibit the lowest values in the biomechanical indices that best reflect the digging ability such as epicondylar development and olecranon index (Fig. 4C and D).

The position of octodontid rodents in the different morphospaces (Fig. 2), allows visualizing clinal variation from epigean to subterranean forms, being noteworthy that epigean and semi-fossorial morphospace have greater overlap with the fossorial species. 
Given such overlap, it is suggested that our categories represent subdivisions of a continuous spectrum of substrate preference or faculties (e.g., digging) which in turn can be aligned with different biological roles (to forage, build shelters, etc; see Vizcaíno et al. (2016) (supplementary material 4 in the supplementary online Appendix). Interestingly, despite the fact that semi-fossorial Tympanoctomys presents slender humerus, radius, and ulna, narrow epicondyles of the humerus, and short olecranon of the ulna with poorly developed processes (Pérez et al., 2017), it has the ability to build complex burrows (Morgan and Verzi, 2006; Lessa et al., 2008). The absence of extreme modifications in the forelimbs, observed in Tympanoctomys, can be related to the fact that this genus occurs in sandy soils, therefore strong adaptations of the limbs are not necessary (Pérez et al., 2017), indicating it is not need of significant mechanical advantage on arm retraction necessary during the digging phase of scratch digging or greater out-force at the level of the metacarpals, for dissociating soil particles during the digging phase (Lagaria and Youlatos, 2006). Among octodontids, further detailed analysis of the digging behavior in habitats with different soil characteristics, as well as other species is required to determine the relationships between morphological adaptations and ecological factors that characterize these morphofunctional associations. Moreover, Tympanoctomys, like other small semi-fossorial rodents such as small ground squirrels (Ammospermophilus, $120 \mathrm{~g}$, and Tamias, $\sim 75 \mathrm{~g}$ ), are less specialized than their larger relatives, their habit of burrowing primarily for shelter and refuge means their specializations need not be as extreme as larger and most burrowing mammals (Elissamburu and Vizcaíno, 2004; Samuels and Van Valkenburgh, 2008). Indeed, the subterranean S. cyanus showed no morphospace overlap with the other categories, as well as, the greater correct classification in discriminant analyses. 
Regarding postcranial measures, our results showed a significant correlation with size. Only HRI was independent of this variable. The morphological specialization patterns are not completely independent or scale by size, there is interspecific allometry. Some biomechanical patterns explained above could be successfully related; and for this reason, despite the smaller body size it may have higher values, both in some of its postcranial measurements and in its indices, and this is the case of Spalacopus, the small subterranean octodontid.

The main outcome of our analysis is the finding of two forelimb traits indicative of adaptive trends, which are consistent with most of those described for other mammals in humerus and ulna (EI and OI respectively; see Milne et al., 2009 for cingulates; Toledo et al., 2012 for pilosans; Elissamburu and Vizcaíno, 2004, and Candela and Picasso, 2008 for caviomorph rodents among others). These morphological features allowed; carpal and digital flexion capabilities as well as forearm extension, which were mostly associated with mechanical requirements for digging (but also climbing; see Toledo et al., 2012 and references therein). This led us to recognize between epigean and subterranean octodontids, and the forelimb morphology seems more similar or conservative in the other members of the family with probably more flexible use of substrate, lacking specialization for one locomotor mode or another, similar to that observed in other rodents (Carvalho Coutinho et al., 2013). Regarding the low phylogenetic signal found, we could think that the species divergences were much deeper, and like Caumul and Polly (2005) mentioned for some morphological traits, the range of phylogenetic usefulness will be influenced by the adaptive response of the trait, which is a function of its genetic control and the strength of selection. 
Further studies are necessary to explore the environmental characteristics, such as soil features, the proportion of roots, and other elements that hinder burrow construction and may influence these patterns of morphological variation. The family Octodontidae is highly specialized and adapted to living in desert habitats with a wide range of lifestyles in just a few genera, so it is expected that the limbs have modified structures for that purpose.

\section{Acknowledgments}

The authors are grateful to Rubén Barquez (Colección Mamíferos Lillo-Universidad Nacional de Tucumán), Ulyses Pardiñas (Centro Nacional Patagónico, Puerto Madryn, Chubut), Diego Verzi (Museo de La Plata, Buenos Aires), Benjamín Bender (IADIZA, Mendoza) and Guillermo D’Elia (UACH, Valdivia, Chile) for allowing access to materials under their care. And to Fredy Mondaca and Santiago Gamboa A. for their assistance at the respective collections. We also thanks to Elkin Suárez-Villota for facilitate their phylogenetic tree proposed for our analysis, Néstor Toledo for their comments on the manuscript, and Marcos Macchioli Grande for improved the English of the manuscript.

This work was supported by a doctoral fellowship of CONICET (Consejo Nacional de Investigaciones Científicas y Técnicas) awarded to MJP.

\section{Conflict of Interest Statement}

The authors declare no conflict of interest.

\section{Supplementary material}

Supplementary material 1. Discriminant analysis.

Supplementary material 2. Biomechanical indices.

Supplementary material 3. Orthonormal decomposition of variance.

Supplementary material 4. phylogenetic Flexible Discriminant Analysis. 


\section{References}

Álvarez, A., 2012. Diversidad morfológica cráneo-mandibular de roedores caviomorfos en un contexto filogenético comparativo. Doctoral Thesis, Facultad de Ciencias Naturales y Museo, Universidad Nacional de La Plata, Argentina.

Álvarez, A., Ercoli, M. D., Olivares, A. I., DeSantis, N. A., Verzi, D. H., 2020.

Evolutionary patterns of mandible shape diversification of caviomorph rodents. J. Mamm. Evol. https://doi.org/10.1007/s10914-020-09511-y

Argot, C., 2001. Functional-Adaptive anatomy of the forelimb in the Didelphidae, and the paleobiology of the Paleocene Marsupials Mayulestes ferox and Pucadelphys andinus. J. Morph. 247:51-79.

Argot, C., 2002. Functional-Adaptive analysis of the hindlimb anatomy of extant Marsupials and Paleobiology of the Paleocene Marsupials Mayulestes ferox and Pucadelphys andinus. J. Morph. 253:76-108.

Argot, C., 2003. Functional-adaptative anatomy of the axial skeleton of some extant marsupials and the paleobiology of the Paleocene marsupials Mayulestes ferox and Pucadelphys andinus. J. Morph. 255:279-300.

Biknevicius, A. R., 1993. Biomechanical scaling of limb bones and differential limb use in caviomorph rodents. J. Mamm. 74:95-107.

Blonder, B., Harris, D. J., 2019. hypervolume: high dimensional geometry and set operations using kernel density estimation, support vector machines, and convex hulls. R package ver. 2.0.12. < https://CRAN.R-project.org/package=hypervolume>

Bloomberg, S. P., Garland, T., Ives, A. R., 2003. Testing for phylogenetic signal in comparative data: behavioral traits are more labile. Evol. 57:717-745. 
Campos, V. E., 2019. Octomys mimax. In: SAyDS-SAREM (eds.) Categorización 2019 de los mamíferos de Argentina según su riesgo de extinción. Lista Roja de los mamíferos de Argentina. Versión digital: http://cma.sarem.org.ar.

Candela, A., Picasso, M._B._J., 2008. Functional Anatomy of the limbs of Erethizontidae (Rodentia, Caviomorpha): indicators of locomotor behavior in Miocene Porcupines. J. Morph. 269:552-593.

Formatted: English (United States)

Cardini, A, Elton, S., 2008. Does the skull carry a phylogenetic signal? Evolution

and modularity in the guenons. Biol. J. of the Linn. Soc.93:813-834.

Carvalho Coutinho, L., de Oliviera, J. A., Pessoa, L. M., 2013. Morphological variation in

Formatted: Spanish (Spain) the appendicular skeleton of atlantic forest sigmodontine rodents. J. Morph.274:779792.

Cassini, G. H. 2013. Skull Geometric morphometrics and paleoecology of santacrucian (Late Early Miocene; Patagonia) native ungulates (Astrapotheria, Litopterna, and Notoungulata). Ameghiniana 50:193-216.

Caumul, R., Polly, P. D., 2005. Phylogenetic and environmental components of morphological variation: skull, mandible, and molar shape in marmots (Marmota, Rodentia). Evolution 59:2460-2472.

Chen, M., Wilson, G._P., 2015. A multivariate approach to infer locomotor modes in Mesozoic mammals. Paleobiol. 41:280-312.

Contreras, L. C., Torres-Mura, J. C., Yáñez J. L., 1987. Biogeography of octodontid rodents: an eco-evolutionary hypothesis, In: Patterson, B. D., Timm, R. E. (Eds.), Studies in Neotropical Mammalogy, Essays in Honor of P. Hershkovitz. Field.: Zool., new series 39, pp. 401-411. 
Elissamburu, A., 2010. Estudio biomecánico y morfofuncional del esqueleto apendicular de Homalodotherium Flower 1873 (Mammalia, Notoungulata). Ameghiniana 47:25-43.

Elissamburu, A., De Santis, L., 2011. Forelimb proportions and fossorial adaptations in the scratch-digging rodent Ctenomys (Caviomorpha). J. Mamm. 92:683-689.

Elissamburu, A., Vizcaíno, S. F., 2004. Limb proportions and adaptations in caviomorph rodents (Rodentia: Caviomorpha). J. Zool. 262:145-159.

Fabre, A. C., Cornette, R. Goswami, A., Peigné, S., 2015. Do constraints associated with the locomotor habitat drive the evolution of forelimb shape? A case study in musteloid carnivorans. J. Anat.226:596-610.

Fernández, M. E., Vassallo, A. I. Zárate, M., 2000. Functional morphology and palaeobiology of the Pliocene rodent Actenomys (Caviomorpha: Octodontidae): the evolution to a subterranean mode of life. Biol. J. Linn. Soc. 71:71-90.

Flores, D. A., 2009. Phylogenetic Analyses of postcranial skeletal morphology in Didelphid marsupials. Bull. Am. Mus. Nat. Hist. 320:1-81.

Flores, D. A., Díaz, M. M., 2009. Postcranial skeleton of Glironia venusta (Didelphimorpha, Didelphidae, Caluromyinae): Descripcion and functional morphology. Zoosyst. Evol.85:311-339.

Gallardo, M. H., Ojeda, R. A., González, C. A. Ríos, C. A., 2007. The Octodontidae revisited, In: Kelt, D. A., Lessa, E., Salazar-Bravo, J., Patton, J. L. (Eds.), The Quintessential Naturalist, Honoring the Life and Legacy of Oliver P. Pearson (. Berkeley: Press Publications in Zoology 134, pp. 695-720.

Hastie, T., Tibshirani, R., Buja, A., 1994. Flexible discriminant analysis by optimal scoring. J. Am. Stat. Assoc. 89:1-41. 
Hildebrand, M., 1985. Digging of quadrupeds. Pp. 90-108 in Functional Vertebrate Morphology (M. Hildebrand, D. M. Bramble, K. F. Liem, and D. B. Wake, eds.). Belknap Press of Harvard University, Cambridge.

Hildebrand, M., Goslow, G., 2001. Analysis of Vertebrate Structure.: John Wiley \& Sons, Inc. New York, USA.

Hedrick, B.P., Dickson, B.V., Dumont, E.R., Pierce, S.E., 2020. The evolutionary diversity of locomotor innovation in rodents is not linked to proximal limb morphology. Sci. Rep., 10:1-11.

Hopkins, S. S. B., Davis, E. B., 2009. Quantitative morphological proxies for fossoriality in small mammals. J. Mamm. 90:1449-1460. https://doi.org/10.1644/08- MAMM-A$\underline{262 \mathrm{R} 1.1}$

Howell, B. A., 1944. Speed in Animals. Their Specialization for Running and Leaping, Chicago: University of Chicago Press.

Jenkins, F. A., Camazine, S. M., 1977. Hip structure and locomotion in ambulatory and cursorial carnivores. J. Zool. (London) 181:351-370.

Kappelman, J., 1988. Morphology and locomotion adaptations of the bovid femur in relation to habitat. J. Morph. 198:119-130.

Kembell, S. W. et al., 2018. Picante: R tools for integrating phylogenies and ecology. Bioinformatics 26:1463-1464.

Klingenberg, C. P., Zimmermann, M., 1992. Static, ontogenetic, and evolutionary allometry: a multivariate comparison in nine species of water striders. Am. Nat. 140: $601-620$.

Lagaria, A., Youlatos, D. 2006. Anatomical correlates to scratch digging in the forelimb of european ground squirrels (Spermophilus citellus). J. Mammal. 87:563-570. 
Lessa, E. P., Vasallo, A. I. Verzi, D. H. Mora M. S., 2008. Evolution of morphological adaptations for digging in living and extinct ctenomyid and octodontid rodents. The Linnean Society of London, Biol. J. Linn. Soc.95:267-283.

Lewis, M. E., 1997. Carnivoran paleoguilds of Africa: Implications for hominid food procurement strategies. J. Hum. Evol. 32:257-288.

Mares, M. A., Ojeda, R. A., 1982. Patterns of diversity and adaptation in South American Hystricognath Rodents, In: Mares, M. A., Genoways, H. H. (Eds.), Mammalian biology in South America. Special Publication Series, 6. (. Pittsburgh, Pennsylvania: University of Pittsburgh, pp. 393-432.

Mares, M._A., Braun, J._K. Barquez, R. M., Díaz, M._M., 2000. Two new genera and Formatted: English (United States) species of halophytic desert mammals from isolated Salt Flats in Argentina. Occasional Papers, Museum of Texas Tech University, 203:1-27.

Martins, E. P., Hansen, T. F., 1997. Phylogenies and the Comparative Method: A General Approach to Incorporating Phylogenetic Information into the Analysis of Interspecific Data. Am. Nat. 149: 646-667. doi:10.1086/286013.

Milne, N, Vizcaíno, S. F., Fernicola, J. C., 2009. A 3D geometric morphometric analysis of digging ability in the extant and fossil cingulate humerus. J. of Zool. 278:48-56.

Moore, T.Y., Rivera, A.M., Biewener, A.A., 2017. Vertical leaping mechanics of the Lesser Egyptian Jerboa reveal specialization for maneuverability rather than elastic energy storage. Front. Zool., 14:1-12.

Morgan, C. C., Álvarez, A., 2013. The humerus of South American caviomorph rodents: shape, function and size in a phylogenetic context. J. Zool. 290:107-116. https://doi.org/10.1111/jzo.12017 
Morgan, C. C., Verzi, D. H., 2006. Morphological diversity of the humerus of the South American subterranean rodent Ctenomys (Rodentia, Ctenomyidae). J. Mamm. 87:1252-1260.

Morgan, C. C., Verzi, D. H., 2011. Carpal-metacarpal specializations for burrowing in South American octodontoid rodents. J. Anat. 219:167-175.

Morgan, C. C., Verzi, D. H., Olivares, A. I., Vieytes, E. C., 2017. Craniodental and forelimb specializations for digging in the South American subterranean rodent Ctenomys (Hystricomorpha, Ctenomyidae). Mamm. Biol. 87:118-124. http://dx.doi.org/10.1016/j.mambio.2017.07.005

Motani, R., Schmitz, L., 2011. Phylogenetic versus functional signals in the evolution of form-function relationships in terrestrial vision. Evol. 65: 2245-2257.

Ojeda, A. A., Novillo, A., Ojeda, R. A., Roig-Juñent, S., 2013. Geographical distribution and ecological diversification of South American octodontid rodents. J. Zool. 289:285-293.

Oksanen, J. F. et al., 2018. vegan: Community ecology package, R package version 1.15-4.

Ollier, S., Couteron, P. Chessel, D., 2006. Orthonormal Transform to Decompose the Variance of a Life-History Trait across a Phylogenetic Tree. Biometrics 62:471-477

Pagel, M., 1999. Inferring historical patterns of biological evolution. Nature 401:877-884.

Pérez, M. J., 2019. Estudio de la forma, función y tamaño de los elementos esqueletales de la familia Octodontidae (Mammalia: Rodentia) en un contexto filogenético. Tesis doctoral, Facultad de Ciencias Naturales e Instituto Miguel Lillo, Universidad Nacional de Tucumán. 
Pérez, M. J., Barquez, R. M., Díaz, M. M., 2017. Morphology of the limbs in the semifossorial desert rodent species of Tympanoctomys (Octodontidae, Rodentia). ZooKeys 710:77-96. https://doi.org/10.3897/zookeys.710.14033

Pérez, M. J., Díaz, M. M., 2018. Octodontomys gliroides (Rodentia: Octodontidae), Mamm. Species 50:74-83. https://doi.org/10.1093/mspecies/sey010

Polly, P. D., 2007. Limbs in mammalian evolution, In: Hall, B.K. (Ed.), Fins into Limbs: Evolution, Development, and Transformation, in (University of Chicago Press, Chicago, pp. 245-268.

R Core Team, 2019 R: A language and environment for statistical computing. R Foundation for Statistical Computing, Vienna, Austria. URL https://www.Rproject.org/.

Radinsky, L. B., 1987. The Evolution of Vertebrate Design. University of Chicago Press, Chicago

Reig, O. A., 1989. Karyotypic repatterning as one triggering factor in cases of explosive speciation, In: Fontdevila, A. (Ed.), Evolutionary Biology of Transient Unstable Populations. (Springer-Verlag, Berlin, pp. 246-289.

Rivera, D. S., Qüense, J., 2019. Octodontomys gliroides. En: SAyDS-SAREM (eds.) Categorización 2019 de los mamíferos de Argentina según su riesgo de extinción. Lista Roja de los mamíferos de Argentina. Versión digital: http://cma.sarem.org.ar.

Samuels, J., Van Valkenburgh, B., 2008. Skeletal Indicators of locomotor adaptations in living and extinct rodents. J. Morph. 269:1387-1411. https://doi.org/10.1002/jmor.10662

Samuels, J. X., Meachen, J. A., Sakai, S. A., 2013. Postcranial morphology and the locomotor habits of living and extinct carnivorans. J. Morph. 274:121-146. 
Sobrero, R., Campos, V. E., Giannoni, S. M., Ebensperger, L. A., 2010. Octomys mimax (Rodentia: Octodontidae). Mamm. Species 42:49-57.

Sobrero, R., Tammone, M. N., 2019. Octodon bridgesi. In: SAyDS-SAREM (eds.) Categorización 2019 de los mamíferos de Argentina según su riesgo de extinción. Lista Roja de los mamíferos de Argentina. Versión digital: http://cma.sarem.org.ar Stein, B. R., 2000. Morphology of subterranean rodents. In: Lacey, E.A., Patton, J.L., Cameron, G.N. (Eds.), Life Underground: The Biology of Subterranean Rodents, Chicago, IL: University of Chicago Press, pp. 19-61.

Strauss, R.E., 2010. Discriminating Groups of Organisms, In: Elewa, A. (Ed.), Morphometrics for Nonmorphometricians, Lecture Notes in Earth Sciences, vol 124 . Springer, Berlin, Heidelberg, pp. 73-91.

Suárez-Villota, E. Y., González-Wevar, C. A., Gallardo, M. H., Vásquez, R. A., Poulin, E., 2016. Filling phylogenetic gaps and the biogeographic relationships of the Octodontidae (Mammalia: Hystricognathi). Mol. Phyl. Evol. 105:96-101.

Tammone, M. N., 2019. Aconaemys fuscus. In: SAyDS-SAREM (eds.) Categorización 2019 de los mamíferos de Argentina según su riesgo de extinción. Lista Roja de los mamíferos de Argentina. Versión digital: http://cma.sarem.org.ar.

Thomason, J. J., 1991. Functional interpretation of locomotory adaptations during equid evolution. Pp. 213-227 in Biomechanics in Evolution (J. M. U. Rayner, and R. J. Woorton, eds). Cambridge: Cambridge University Press.

Toledo, N., Bargo, M. S., Cassini, G. H., Vizcaíno, S. F., 2012. The forelimb of early Miocene sloths (Mammalia, Xenarthra, Folivora): morphometrics and functional implications for substrate preferences. J. Mamm. Evol. 19:185-198. 
Toledo, N., Muñoz, N. A., Cassini, G. H., 2020. Ulna of extant xenarthrans: shape, size, and function. J. Mamm. Evol. doi.org/10.1007/s10914-020-09503-y.

Torres-Mura, J. C., Contreras, L. C., 1998. Spalacopus cyanus. Mamm. Species. 594:1-5.

Van Valkenburgh, B., 1987. Skeletal indicators of locomotor behavior in living and extinct carnivores. J. Vert. Paleont. 7:162-182.

Vassallo, A. I., 1998. Functional morphology, comparative behaviour, and adaptation in two sympatric subterranean rodents genus Ctenomys (Caviomorpha: Octodontidae). J. Zool. (London) 244:415-427.

Vassallo, A. I., Becerra, F., Echeverría, A. I., Díaz, A. O., Longo, M. V., Cohen, M., Buezas, G. N., 2019. Analysis of the form-function relationship: digging behavior as a case study. J. Mamm. Evol. doi.org/10.1007/s10914-019-09492-7

Verde Arregoitia, L. D., Fisher, D. O., Schweizer, M., 2016. Morphology captures diet and locomotor types in rodents. R. Soc. Open Sci. 4:160957.

Verzi, D. H., Olivares, A. I., 2006. Craniomandibular joint in South American burrowing rodents (Ctenomyidae): adaptations and constraints related to a specialized mandibular position in digging. J. Zool. 270:488-501.

Verzi, D. H., Díaz, M. M., Barquez, R. M., 2015. Family Octodontidae, In: Patton, J.L., Pardiñas, U.F.J., D'Elía, G. (Eds.), Mammals of South America. Volume 2, Rodents University of Chicago Press, Chicago, pp. 1023-1048.

Verzi, D. H., Olivares, A. I., Morgan, C. C., 2014. Phylogeny and evolutionary patterns of South American octodontoid rodents. Acta Palaeontol. Pol. 59: 757-769.

Verzi, D. H., Tonni, E. P., Scaglia, O. A., San Cristóbal, J. O., 2002. The fossil record of the desert-adapted South American rodent Tympanoctomys (Rodentia, Octodontidae). 
Paleoenvironmental and biogeographic significance. Palaeogeograph., Palaeoclimatol., Palaeoecol. 179:149-158.

Vizcaíno, S. F., Bargo, M. S., 2019. Views on the form-function correlation and biological design. J. Mamm. Evol.doi.org/10.1007/s10914-019-09487-4.

Vizcaíno, S.F., Milne, N., 2002. Structure and function in armadillo limbs (Mammalia: Xenarthra: Dasypodidae). J. Zool. 257:117-127.

Vizcaíno, S. F., Fariña, R. A., Mazzetta, G. V., 1999. Ulnar dimensions and fossoriality in armadillos. Acta Theriológica. 44:309-320.

Vizcaíno, S. F., Bargo, M. S., Cassini, G. H., Toledo, N., 2016. Forma y Función en Paleobiología de Vertebrados. Editorial de la Universidad Nacional de La Plata (EDULP), La Plata.

Vucetich, M.G., Arnal, M., Deschamps, C.M., Pérez, M.E., Vieytes, E.C., 2015. A brief history of caviomorph rodents as told by the fossil record, In: Vasallo, A.I., Antenucci, D. (Eds.), Biology of Caviomorph Rodents: Diversity and Evolution. SAREM Series A-Mammalogical Research, Buenos Aires, Vol 1, pp. 11-62.

Warton, D. I., Weber, N. C., 2002. Common slope tests for bivariate errors- in- variables models. Biometrical J. 44:161-174.

Warton, D. I., Wright, I. J., Falster, D. S., Westoby, M., 2006. Bivariate line-fitting methods for allometry. Biol. Rev. 81:259-291. 
Appendix. List of specimens analyzed detailing the number of individuals by species in brackets, collection localities, type specimens, and collection numbers are indicated. See Materials and Methods by collections acronyms.

Aconaemys fuscus (2): CHILE, Ñuble, Quillón, Hacienda El Roble, 2 (UACH 4181, 4183).

Aconaemys porteri (20): ARGENTINA: NEUQUÉN, Dpto. Huiliches: Lago Curruhué Grande, 1 (MLP 17.II.92.7); Parque Nacional Lanín, entre Lago Curruhé y Lago Curruhé Chico, 3 (MLP 17.II.92.1, 17.II.92.2, 17.II.92.3); Parque Nacional Lanín, Volcán Huanquihue, 1 (MLP 17.II.92.4). CHILE, CAUTÍN, Villarrica: Parque Nacional Villarrica - Quetropillán, 14 (UACH 3705, 3706, 3707, 3708, 3709, 3710, 3711, 3712, 3715, 3723, 4184, 4191, 4192, 4193); OSORNO, Entre Lagos: Parque Nacional Puyehue, 1 (UACH 3701).

Aconaemys sagei (3): ARGENTINA: NEUQUÉN, Dpto. Aluminé: Parque Nacional Lanín, Pampa de Hui Hui, 1 (MLP 17.II.92.08); Parque Nacional Lanín, Lago Ñorquinco, 1 (MLP

17.II.92.11). CHILE: MALLECO, Collipulli: Parque Nacional Tolhuaca, 1 (UACH 3703).

Octodon bridgesi (4): CHILE: ÑUBLE, Coelemu: Burca - Fundo La Madera, 1 (UACH

3146); QUIRIHUE: Las Eras, 2 (UACH 3876, 3880); Los Remates, 1 (UACH 4328).

Octodon degus (1): CHILE: QUILLOTA: Parque Nacional La Campana-V Región, 1 (MLP 12.XI.02.15).

Octodon sp. (4): ARGENTINA: NEUQUÉN, Dpto. Huiliches: Parque Nacional Lanín, Lago Curruhué Chico, 2 (MLP 12.VII.88.3, 12.VII.88.5); Parque Nacional Lanín, entre Lago Curruhé y Lago Curruhé Chico, 2 (MLP 12.VII.88.6, 12.VII.88.7). 
Octodontomys gliroides (12): ARGENTINA: JUJUY, Dpto. Cochinoca: Mina Pirquitas, 31 km al SE sobre ruta 74 b. Sa. De Quichagua, 4200 m, 1 (CML 7137); Dpto. Rinconada: Mina Pan de Azúcar, 8 km al N y 5 km al W camino a Herrana, 3820 m, 2 (CML 7138, 7140); Dpto. Santa Catalina: "Cuesta del Hurón", 29 km al W de Cieneguillas sobre ruta prov. 64, 3835m, 3 (CML 7143, 7144, 7145); Dpto. Susques: Curques, 24 km al N de Susques, sobre ruta 74, 4100 m, 1 (CML 7146); Dpto. Tumbaya: sobre ruta 52, Cuesta de Lipán, 15 km al W de Purmamarca, 3156 m, 1 (CML 7148), Dpto. Yavi, 1 (CML 2872); SALTA, Dpto. Los Andes: 36 km N San Antonio de Los Cobres, 11600 feet, 1 (CML 9393). CHILE: PARINACOTA, Putre: Chapiquiña (Murmutani), 2 (UACH 2463, 2464).

Octomys mimax (3): ARGENTINA: LA RIOJA, Dpto. Gral. Lamadrid: Villa Castelli, Cerro del Toro 1 (CML 13065); SAN JUAN, Dpto. Valle Fértil: Parque Provincial Ischigualasto, 2 (CMI 6844, 6847).

Spalacopus cyanus (11): CHILE: CHOAPA, Los Vilos: Los Vilos, 1 (UACH 2510); Com. Quirihue, Los Remates, 2 (UACH 4017, 4018); NUBLE, Con. Quirihue, Los Remates, 22 (1 MLP 10.XI. 95.5; 7 UACH 4002, 4003, 4006, 4012, 4368, 4376, 4385).

Tympanoctomys aureus (17): ARGENTINA: CATAMARCA, Dpto. Andalgalá: Salar de Pipanaco, 5 km del puesto de Pío Brizuela, entrada km 96 sobre R46, 1 (CMI 7188), 10 km de Pío Brizuela (Est. Río Blanco), km 96 sobre R46, 35 km S de Andalgalá, 1 (CMI 6818); Dpto. Pomán: Establecimiento Río Blanco, 28 km S, 9.3 km W Andalgalá, 3 (CML 4136, 4137-paratypes, 6137-holotype), Pipanaco, Salar Pipanaco, 3 (CMI 6846, 6848, 6856), Salar de Pipanaco, 35 km S de Andalgalá, 1 (CMI 6565), 35 km S de Andalgalá a 10 km de la Casa Est. Río Blanco en los bordes del Salar Pipanaco, 3 (CMI 6562, 6563, 6564), 35 km al S de Andalgalá (R46) a 10 km del puesto Pío Brizuela (Establ. Río Blanco), 1 (CMI 
6888), 35 Km S de Andalgalá (Ruta 46) y a 13 km de la entrada Establecimiento Río Blanco, 4 (CMI 6558, 6559, 6560, 6561).

Tympanoctomys barrerae (14): ARGENTINA: LA PAMPA, Dpto. de Limay, Mahuida, 6 (CMI 6877, 6878, 6879, 6880, 6882, 6883); MENDOZA, Dpto. La Paz: 27 km N Desaguadero, 556 m app, 1 (CMI 3438), Desaguadero, El Tapón 37 km, 1 (CMI 3314); Dpto. Malargüe, a 8.5 km camino a Llancanelo, 1 (CMI 7098); Dpto. San Rafael: 10 km S El Nihuil, 2 (CMI 3845, 3846); SAN JUAN, Dpto. Valle Fértil: Parque Provincial Ischigualasto, 3 (CMI 6842, 6843, 6853).

Tympanoctomys kirchnerorum (2): ARGENTINA: CHUBUT, Dpto. Sarmiento: Ea. La Porfía, 2 (CNP 2503, 2505-paratypes).

Tympanoctomys loschalchalerosorum (1): ARGENTINA: LA RIOJA, Dpto. Chamical: 26 km SW Quimilo, 581 m 150 m, 1 (CML 3695-holotype). 
$770=10 \mathrm{~cm}$ analysis.

\section{Figure captions}

Figure 1. Measurements of the humerus and ulna. APDH, anteroposterior diameter of the humerus; DEH, diameter of the epicondyles; DLH, deltoid length of the humerus; FHL, functional humerus length; FUL, functional ulna length; OL, length of the olecranon process; TDU, transverse diameter of the ulna.

Figure 2. Morphospaces depicted by the two first principal components showing A) species distributions with superimposed phylomorphospace and B) substrate use clustering. Symbols size are proportional to the weight.

Figure 3. Misclassification of octodontids on the basis of phylogenetic flexible discriminant

Figure 4. Humerus in posterior view and ulna in anterior view. A) Aconaemys fuscus; B) Octodon bridgesi; C) Octodontomys gliroides; D) Octomys mimax; E) Spalacopus cyanus and F) Tympanoctomys loschalchalerosorum (humerus) and T. barrerae (ulna). Scale bars 


\section{Tables}

773 Table 1. The arithmetic mean $\pm s d(n)$ of the functional indices used in this study.

774 Acronyms as explained in the Materials and Methods section.

775

\begin{tabular}{|c|c|c|c|c|c|}
\hline Species & SMI & HRI & EI & URI & OI \\
\hline \multirow{3}{*}{ Aconaemys fuscus } & $46.89 \pm 1.58$ & $8.68 \pm 0.03$ & $25.92 \pm 0.34$ & $4.44 \pm 0.02$ & $18.61 \pm 5.20$ \\
\hline & & & & & \\
\hline & (2) & (2) & (2) & (2) & (2) \\
\hline \multirow[b]{2}{*}{ Aconaemys porteri } & $43.94 \pm 4.22$ & $9.3 \pm 0.48$ & $26.04 \pm 1.76$ & $4.32 \pm 0.22$ & $18.13 \pm 1.04$ \\
\hline & (20) & (20) & (20) & (20) & (20) \\
\hline \multirow{3}{*}{ Aconaemys sagei } & $42.38 \pm 6.16$ & $9.69 \pm 1.06$ & $26.20 \pm 1.37$ & $4.51 \pm 0.38$ & $17.86 \pm 1.76$ \\
\hline & & & & & \\
\hline & (3) & (3) & (3) & (3) & (3) \\
\hline \multirow{3}{*}{ Octodon bridgesi } & $43.96 \pm 4.13$ & $8.87 \pm 0.95$ & $24.89 \pm 3.72$ & $3.56 \pm 0.14$ & $16.63 \pm 5.22$ \\
\hline & & & & & \\
\hline & (4) & (4) & (4) & (4) & (4) \\
\hline \multirow{3}{*}{ Octodon degus } & 43.85 & 8.84 & 24.34 & 5.07 & 16.85 \\
\hline & & & & & \\
\hline & (1) & (1) & (1) & (1) & (1) \\
\hline \multirow{3}{*}{ Octodon sp. } & $40.22 \pm 0.22$ & $9.47 \pm 0.34$ & $24.52 \pm 4.15$ & $4.072 \pm 0.05$ & $14.76 \pm 4.32$ \\
\hline & & & & & \\
\hline & (4) & (4) & (4) & (4) & (4) \\
\hline \multirow[b]{2}{*}{ Octodontomys gliroides } & $42.99 \pm 2.71$ & $9.78 \pm 0.86$ & $20.66 \pm 0.99$ & $3.84 \pm 0.31$ & $14.36 \pm 1.12$ \\
\hline & (12) & (12) & (12) & (6) & (6) \\
\hline \multirow{3}{*}{ Octomys mimax } & $42.12 \pm 5.93$ & $8.81 \pm 0.36$ & $20.90 \pm 1.02$ & $3.40 \pm 0.02$ & $13.59 \pm 3.23$ \\
\hline & (?) & (2) & (2) & (2) & (2) \\
\hline & (J) & (J) & (J) & (3) & (3) \\
\hline \multirow{2}{*}{ Tympanoctomys aureus } & $44.64 \pm 3.06$ & $9.41 \pm 0.51$ & $22.61 \pm 0.85$ & $4.07 \pm 0.76$ & $15.71 \pm 3.18$ \\
\hline & (17) & (17) & (17) & (2) & (2) \\
\hline
\end{tabular}


Tympanoctomys barrerae

Tympanoctomys
kirchnerorum
Tympanoctomys
loschalchalerosorum
Spalacopus cyanus

$42.52 \pm 6.92 \quad 8.71$

(14)

$41.77 \pm 2.32$

(2)

41.56

(1)

$44.2 \pm 3.04$

(11)
$8.71 \pm 0.51$

(14)

$8.71 \pm 0.01$

(2)

7.86

(1)

$7.90 \pm 0.32$

(11)
$3.55 \pm 0.48$

(4)

(14)

$21.86 \pm 0.07$

(2)

21.28

2)

$13.53 \pm 0.92$

(1)

(4)

-

$\begin{array}{lll} & 22 \pm 0.96 & 4.06 \pm 0.22 \quad 19.86 \pm 1.69\end{array}$

(11) (11)

(11)

776

777

778 

included.

\begin{tabular}{|c|c|c|c|c|c|c|}
\hline Index & Statistics & $\begin{array}{c}\text { Observed } \\
\text { value }\end{array}$ & St. Dev. & $p$-value & $K$ statistic & $p$-value \\
\hline \multirow{4}{*}{ EI } & $R^{2} \operatorname{Max}$ & 0.40 & 0.98 & 0.33 & \multirow{4}{*}{1.72} & \multirow{4}{*}{0.001} \\
\hline & $S k R^{2} k$ & 4.47 & -1.31 & 0.18 & & \\
\hline & $D \max$ & 0.44 & 2.24 & $0.03^{*}$ & & \\
\hline & $S C E$ & 0.44 & 0.93 & 0.13 & & \\
\hline \multirow{4}{*}{ HRI } & $R^{2} \operatorname{Max}$ & 0.28 & -0.86 & 0.42 & \multirow{4}{*}{0.43} & \multirow{4}{*}{0.35} \\
\hline & $S k R^{2} k$ & 4.59 & -1.09 & 0.27 & & \\
\hline & Dmax & 0.32 & 1.19 & 0.26 & & \\
\hline & $S C E$ & 0.27 & -0.13 & 0.90 & & \\
\hline \multirow{4}{*}{ SMI } & $R^{2} \operatorname{Max}$ & 0.50 & 1.15 & 0.29 & \multirow{4}{*}{0.20} & \multirow{4}{*}{0.88} \\
\hline & $\mathrm{SkR}^{2} \mathrm{k}$ & 7.49 & 1.19 & 0.24 & & \\
\hline & Dmax & 0.06 & -0.93 & 0.37 & & \\
\hline & $S C E$ & 0.37 & 0.39 & 0.69 & & \\
\hline \multirow{4}{*}{ OI } & $R^{2} \operatorname{Max}$ & 0.44 & 0.56 & 0.54 & \multirow{4}{*}{1.24} & \multirow{4}{*}{0.01} \\
\hline & $S k R^{2} k$ & 6.26 & 1.16 & 0.25 & & \\
\hline & Dmax & 6.28 e- 18 & -1.36 & 0.20 & & \\
\hline & $S C E$ & 0.28 & 0.11 & 0.91 & & \\
\hline \multirow{4}{*}{ URI } & $R^{2} \operatorname{Max}$ & 0.41 & 0.25 & 0.83 & \multirow{4}{*}{0.75} & \multirow{4}{*}{0.2} \\
\hline & $S k R^{2} k$ & 4.87 & -0.12 & 0.91 & & \\
\hline & Dmax & 0.21 & 0.23 & 0.83 & & \\
\hline & $S C E$ & 0.16 & -0.42 & 0.67 & & \\
\hline
\end{tabular}

Table 2. Results from orthogram decomposition analysis for each biomechanical index based on 10,000 Monte Carlo permutations. Observed values, standard deviation (St. Dev), and $p$-values are provided for each statistic. $K$ statistic and $p$ values for each index are also 
786

\begin{tabular}{|c|c|c|c|c|c|c|c|}
\hline Variable & $R^{2}$ & $p$-value & $a$ & $b$ & $p_{\text {iso-value }}$ & $95 \% \mathrm{CI}$ & Trend \\
\hline APDH & 0.5837 & $<0.001$ & -1.124 & 1.8675 & $<0.0001$ & $1.577-2.211$ & + \\
\hline DEH & 0.263 & $<0.001$ & -0.2848 & 1.3463 & 0.0096 & $1.076-1.684$ & + \\
\hline DLH & 0.7117 & $<0.001$ & 0.1436 & 1.0984 & 0.1877 & $0.954-1.264$ & iso \\
\hline FHL & 0.6512 & $<0.001$ & 0.5303 & 1.0665 & 0.4094 & $0.914-1.245$ & iso \\
\hline FUL & 0.4975 & $<0.001$ & 0.3699 & 1.3643 & 0.0013 & $1.134-1.642$ & + \\
\hline $\mathrm{OL}$ & 0.4527 & $<0.001$ & -0.5409 & 1.4613 & 0.0002 & $1.204-1.773$ & + \\
\hline TDU & 0.4416 & $<0.001$ & -1.3001 & 1.7304 & $<0.0001$ & $1.424-2.103$ & + \\
\hline EI & 0.699 & $<0.001$ & -0.3771 & 1.5245 & $<0.0001$ & $1.320-1.760$ & + \\
\hline HRI & 0.0488 & $* 0.08$ & -0.6419 & 1.3677 & & $1.061-1.763$ & \\
\hline SMI & 0.2218 & 0.005 & 0.8111 & 0.7107 & 0.0039 & $0.565-0.894$ & - \\
\hline OI & 0.706 & $<0.001$ & -1.099 & 2.003 & $<0.0001$ & $1.738-2.309$ & + \\
\hline URI & 0.5741 & $<0.001$ & -1.553 & 1.8549 & $<0.0001$ & $1.564-2.200$ & + \\
\hline
\end{tabular}

787

788

789

790

791

792

793

794

Table 3. Standardized major axis regressions results of forelimb log-10 transformed measurements and indices against log-10 transformed GM.

86

Abbreviations: $\boldsymbol{a}$, intercept; $\boldsymbol{b}$, slope; $R^{2}$, coefficient of determination; $p_{\text {iso }}, p$-value of isometry; the $95 \%$ confidence interval is provided; iso, isometric trend, no significant differences from the expected value of one; and $(+)$ positive allometric trend, slope significantly different from the expected value of one. Asterisk (*) indicate a nonsignificant relationship. 
795

796

797

\begin{tabular}{|c|c|c|}
\hline Variable & PC 1 & $\mathrm{PC} 2$ \\
\hline EI & 0.34 & -0.15 \\
\hline HRI & -0.73 & -0.21 \\
\hline SMI & -0.2 & -0.21 \\
\hline $\mathrm{OI}$ & 0.55 & -0.32 \\
\hline URI & - & 0.88 \\
\hline$\%$ explained variance & $52 \%$ & $29 \%$ \\
\hline
\end{tabular}

798

Bold: indicates the values of the highest and lowest loading on each axis explained in the text. 


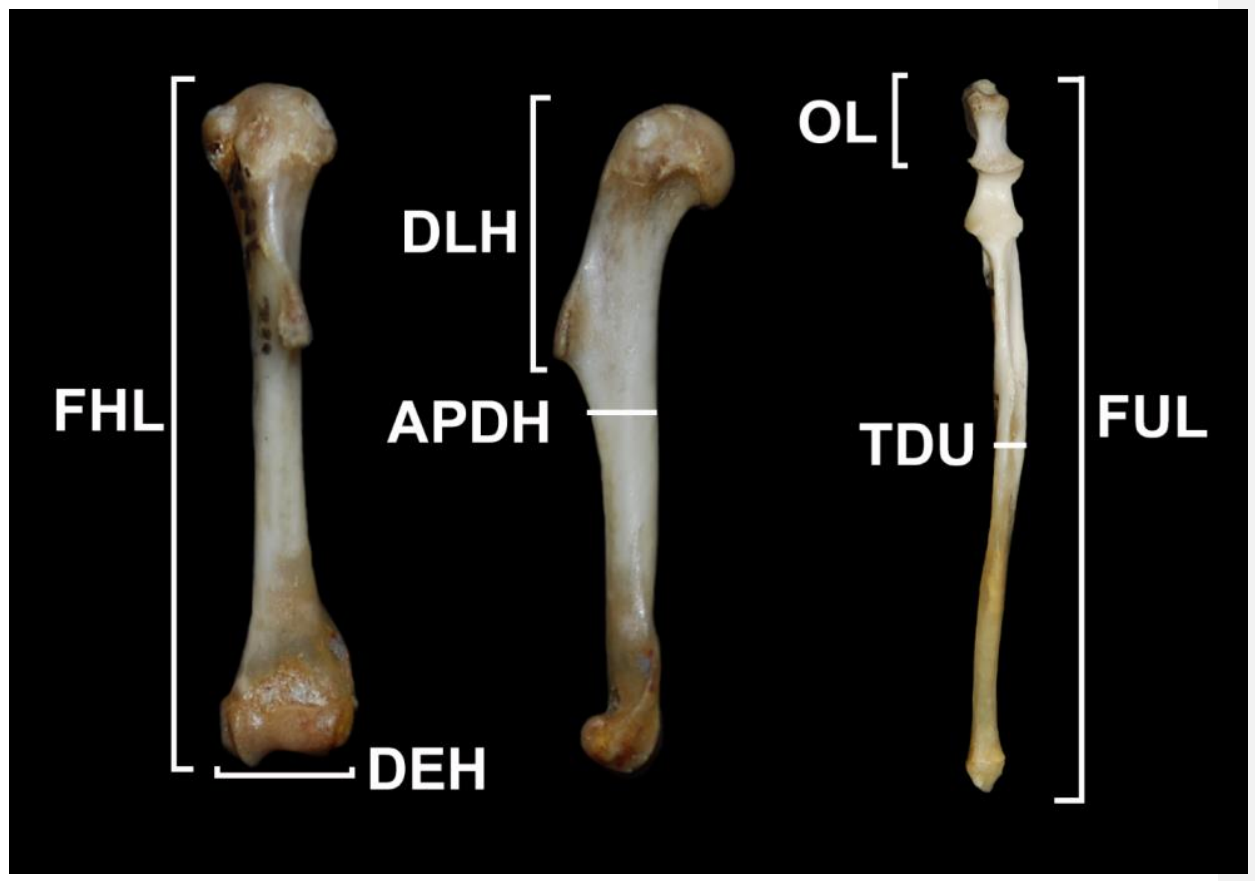



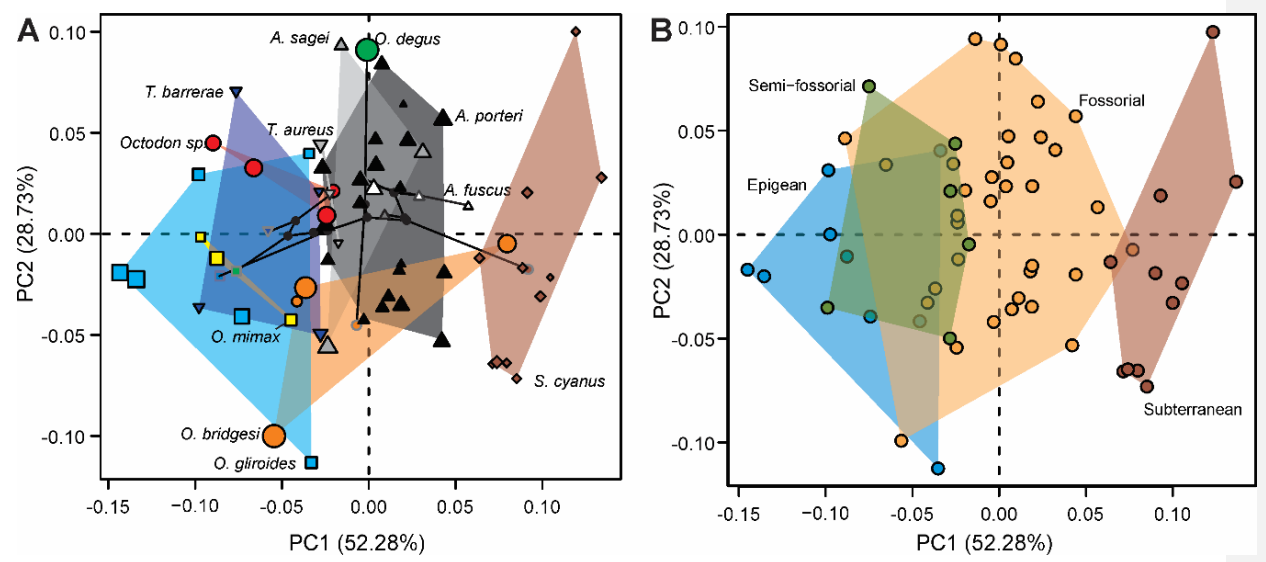
806

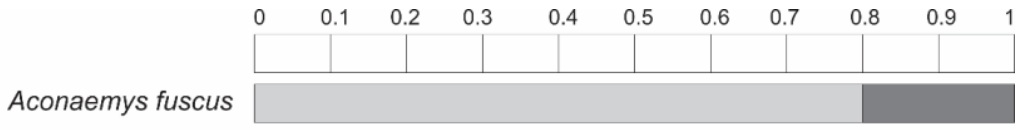

807

Octodon bridgesi

Octodon degus

Tympanoctomys aureus

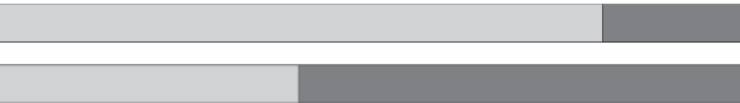

808

809

810 

The forelimbs of Octodontidae (Rodentia: Mammalia): substrate use, morphology and phylogenetical signal

M. Julieta Pérez*, Guillermo H. Cassini and M. Mónica Díaz

Supplementary Material 1 - Discriminant Analysis

\section{Materials and Methods}

A Discriminant Analysis (DA) was performed on two data sets: (1) the whole sample with three biomechanical indices (SMI, HRI, and EI) and (2) the five biomechanical indices removing two species with missing data (Tympanoctomys kirchnerorum and T. loschalchalerosorum). The DA aimed to determine the combination of variables, i.e., morphofunctional indices, that maximizes the separation of octodontid species in relation to the ecological categories recognized in the group. The ability of the discriminant model was tested by analyzing the confusion matrices of the reclassifications (i.e., same data used to construct the function) and by the cross-validation method (or leaving only one), so by over-fitting is avoided by predicting group affiliation using discriminant functions based on samples that do not include the specimens that are being classified. The analyses were carried out with the MASS v.7.3-47 R-package (Venables and Ripley, 2002).

\section{Results}

In the Discriminant Analysis (DA) performed in the whole sample (94 specimens), three biomechanical indices SMI, HRI, and El were considered. The confusion matrix showed that fossorial, semi-fossorial, and subterranean categories have a higher percentage of correct classifications $(>80 \%)$, followed by the epigean group $(\sim 67 \%)$. This scheme repeats on crossvalidation results (Table S1.1). The analysis showed two discriminant functions that accumulate $100 \%$ of the trace. The first discriminant function (DF1) accumulated $96 \%$ of the trace and correlated positively with the El and negatively with the HRI (Table S1.2). The morphospace depicted by these two DF showed a continuous spectrum from epigean to subterranean categories. It is noteworthy that, on the one hand, the semi-fossorial partially overlap with epigean to the left and fossorial to the right and on the other hand the fossorial partially overlap with semi-fossorial to the left and subterranean to the right (Fig. S1.1).

Table S1.1. Discriminant analysis classification matrix for the whole sample. E (Epigeans), SF (Semi-fossorials, F (fossorials) y $S$ (subterraneans). The shaded cells correspond to correct reclassified cases (original data) or classifications (cross-validation).

\begin{tabular}{c|cccccc}
\hline & $\begin{array}{c}\text { Observed } \\
\text { Group }\end{array}$ & \multicolumn{5}{c}{ Predicted Group } \\
\hline \multirow{5}{*}{ Original } & & $\mathrm{E}$ & $\mathrm{SF}$ & $\mathrm{F}$ & $\mathrm{S}$ & $\%$ \\
& $\mathrm{E}$ & $\mathbf{1 0}$ & 5 & 0 & 0 & 66.6 \\
& $\mathrm{SF}$ & 3 & $\mathbf{2 9}$ & 2 & 0 & 80.5 \\
& $\mathrm{~F}$ & 0 & 1 & $\mathbf{3 1}$ & 2 & 91.2 \\
& $\mathrm{~S}$ & 0 & 0 & 1 & $\mathbf{1 0}$ & 91 \\
\hline \multirow{5}{*}{ Cross } & $\mathrm{E}$ & $\mathbf{8}$ & 7 & 0 & 0 & 53.3 \\
Validation & $\mathrm{SF}$ & $\mathbf{3}$ & $\mathbf{2 9}$ & 2 & 0 & 80.5 \\
& $\mathrm{~F}$ & 0 & 3 & $\mathbf{2 9}$ & 2 & 85.3 \\
& $\mathrm{~S}$ & 0 & 0 & 1 & $\mathbf{1 0}$ & 91 \\
\hline
\end{tabular}

Table S1.2. Loadings of each variable for the two first axes in both three and five indices DA. See the text for measurement acronyms.

\begin{tabular}{lcc|cc}
\hline \multirow{2}{*}{ Variables } & \multicolumn{2}{c|}{ Three indices } & \multicolumn{2}{c}{ Five indices } \\
\cline { 2 - 5 } & DF1 & DF2 & DF1 & DF2 \\
\hline EI & $\mathbf{0 . 8 4}$ & -0.17 & $\mathbf{0 . 7 0}$ & 0.22 \\
HRI & $\mathbf{- 0 . 5 4}$ & $\mathbf{- 1 . 2}$ & -0.45 & $\mathbf{1 . 0 9}$ \\
SMI & -0.14 & 0.16 & -0.15 & -0.05 \\
OI & - & - & 0.19 & -0.21 \\
URI & - & - & -0.12 & $\mathbf{0 . 9 8}$ \\
\hline $\begin{array}{l}\text { \% explained } \\
\text { variance }\end{array}$ & $96 \%$ & $4 \%$ & $88 \%$ & $10 \%$ \\
\hline
\end{tabular}

Bold: indicates the values of the highest and lowest loading on each axis.

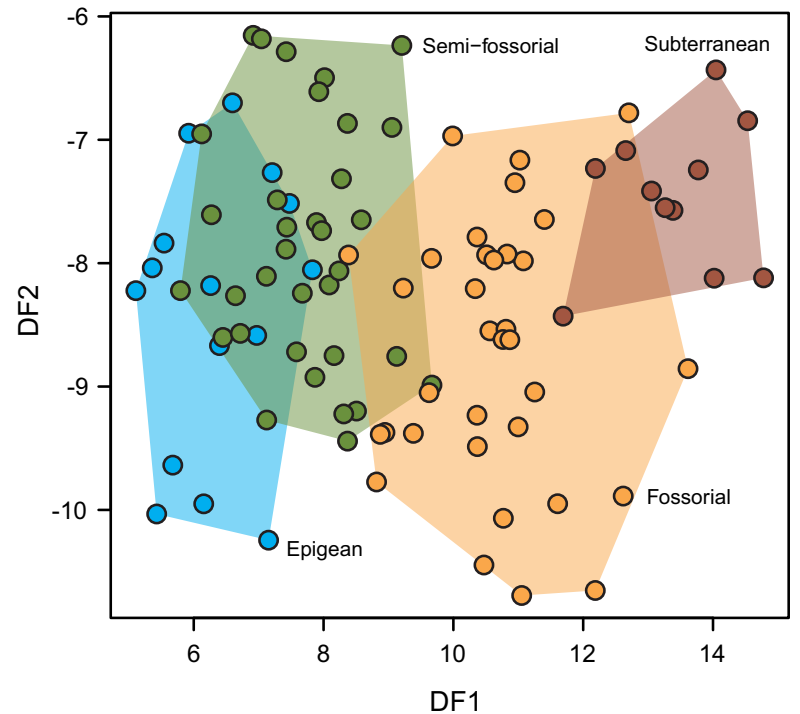

Figure S1.1. Morphospace depicted by the two first discriminant functions for three indices discriminant functions. 
The forelimbs of Octodontidae (Rodentia: Mammalia): substrate use, morphology and phylogenetical signal

M. Julieta Pérez*, Guillermo H. Cassini and M. Mónica Díaz

\section{Supplementary Material 1 - Discriminant Analysis}

In the DA performed with five biomechanical indices, the specimens with missing data (mainly those belonging to Tympanoctomys kirchnerorum and T. loschalchalerosorum) were not included. In general, the values of correct classifications were slightly lower in the cross-validation confusion matrix (Table S.1.3, Fig. S1.2). The cross-validation confusion matrix showed $82 \%$ of the correct ordering of the individuals. The fossorial and subterranean species showed $91 \%$ in the correct classification of their individuals, while epigean and semi-fossorial taxa, below $60 \%$. Most of the misclassifications were individual specimens rather than complete species. In the Tympanoctomys species (T. aureus and T. barrerae), only three of the six specimens were classified as semi-fossorial, and erroneously two were classified as epigeous and one as fossorial. The analysis showed two discriminant functions that accumulate $98 \%$ of the trace. The first discriminant function (DF1) accumulated $88 \%$ of the trace and correlated positively with the El and negatively with the HRI (Table S.1.3). The DF2 only accumulated $10 \%$ of the trace without a clear correlation.

Table S1.3. Discriminant analysis classification matrix for the five indices. E (Epigeans), SF (Semi-fossorials, F (fossorials) y $S$ (subterraneans). The shaded cells correspond to correct reclassified cases (original data) or classifications (cross-validation).

\begin{tabular}{|c|c|c|c|c|c|c|}
\hline & Observed & \multicolumn{5}{|c|}{ Predicted Group } \\
\hline \multirow{5}{*}{ Original } & \multirow[b]{2}{*}{$E$} & $E$ & SF & $\mathrm{F}$ & $S$ & $\%$ \\
\hline & & 8 & 1 & 0 & 0 & $88.8 \%$ \\
\hline & SF & 1 & 4 & 1 & 0 & $66.6 \%$ \\
\hline & $F$ & 0 & 1 & 32 & 1 & $94 \%$ \\
\hline & $S$ & 0 & 0 & 1 & 10 & $91 \%$ \\
\hline \multirow[b]{2}{*}{ Cross } & $E$ & 5 & 4 & 0 & 0 & $55 \%$ \\
\hline & SF & 2 & 3 & 1 & 0 & $50 \%$ \\
\hline \multirow[t]{2}{*}{ Validation } & $F$ & 0 & 2 & 31 & 1 & $91 \%$ \\
\hline & $S$ & 0 & 0 & 1 & 10 & $91 \%$ \\
\hline
\end{tabular}

In both DA, subterranean octodontids had positive values for the DF1 reflecting the tendency to show a greater distance between epicondyles, while the epigeous are associated with negative values, characterized by greater robustness of the humerus; these extremes are clearly differentiated. In the morphospace depicted by these two discriminant function, the epigeous taxa were placed close to the semi-fossorial group, followed by the fossorial taxa and finally the subterranean group located on the other end.

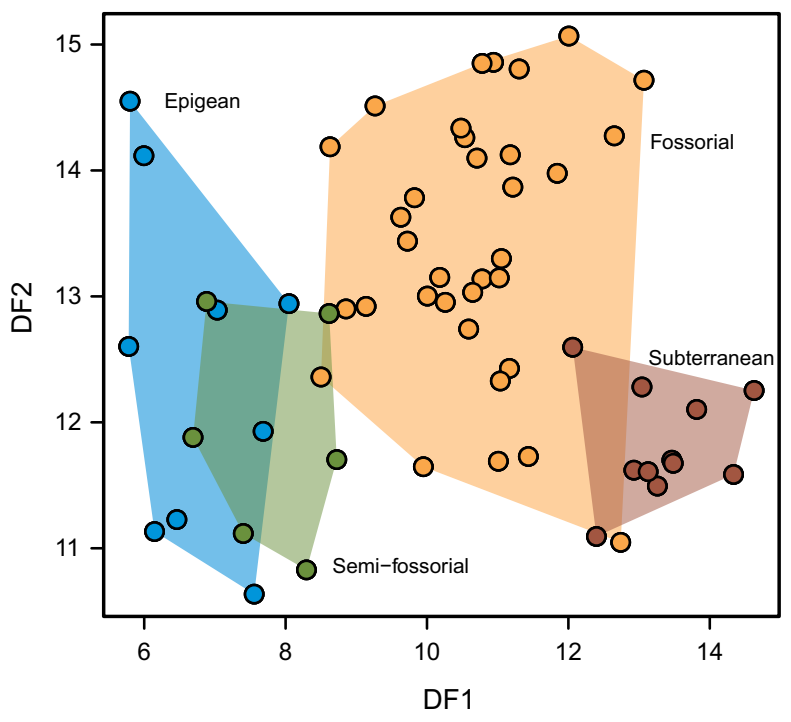

Figure S1.2. Morphospace depicted by the two first discriminant functions for five indices discriminant functions.

\section{Discussion}

The results of both data sets, the whole sample with three indices concerning only the humerus and a subsample for which all five indices can be calculated (including those of the ulna), showed that fossorial and subterranean groups showed the highest correct classification. These two categories were the best represented in the two DA. Those species classified as epigean were clustered toward the left side of the morphospace ( $\sim 6$ value) and the subterranean toward the right side of the morphospace ( 14 value). The semi-fossorial category was the group with more ulnae missing data. The results of DA were consistent with the phylogenetic Flexible Discriminant Analysis (pFDA), and the El proved to be one of the variables that most contributed to the discriminant functions (DF). Moreover, no significant differences were recorded among both discriminant analyses (phylogenetic and non-phylogenetic).

\section{References}

Venables, W.N., Ripley, B.D., 2002. Modern Applied Statistics with S. Fourth Edition. Springer, New York 481 pp. 
The forelimbs of Octodontidae (Rodentia: Mammalia): substrate use, morphology and phylogenetical signal
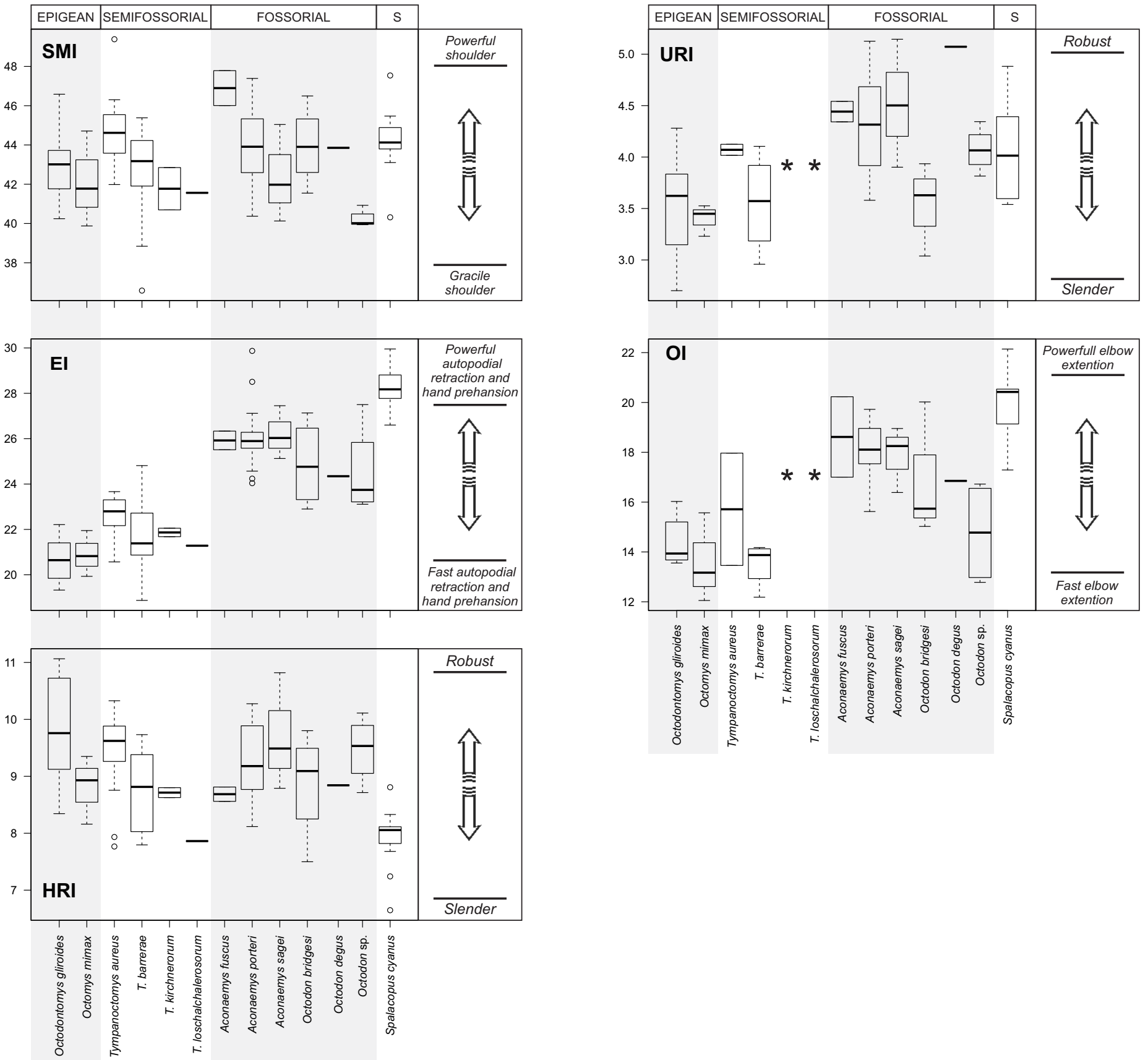

Figure S2.1. Biomechanical indices for each genus indicating median (middle bar), 25th percentile, 75th percentile (inferior and superior edges of boxes), minimum, and maximum values. Abbreviations: SMI, shoulder moment index; HRI, humerus robustness index; El, epicondylar index; URI, ulnar robustness index; OI, olecranon index. Asterisks represent missing data. S. Subterranean.

From text. - Among the rock rats (genus Aconaemys), A. fuscus showed the highest values for shoulder moment index (SMI) also compared to all other species, as well as the olecranon index (OI), while $A$. sagei had the highest epicondylar development in the humerus (EI), as well as the more robust humerus (HRI) and ulna (URI). In the degus (genus Octodon), O. bridgesi had the highest SMI and EI, while O. degus exhibited high URI and the highest $O I$. Among vizcacha rats species (genus Tympanoctomys), $T$. aureus exhibited the highest values almost for all the calculated indices (unknown URI and OI for T. kirchnerorum and $T$. loschalchalerosorum), sharing the same El value than $T$. barrerae. The mountain degu, Octodontomys gliroides, had the highest HRI compared to all species considered here, while Octomys mimax showed the lowest URI. Finally, the coruro (Spalacopus cyanus) had the highest El and Ol compared to all studied species. 
The forelimbs of Octodontidae (Rodentia: Mammalia): substrate use, morphology and phylogenetical signal

M. Julieta Pérez*, Guillermo H. Cassini and M. Mónica Díaz

\section{Supplementary Material 3 - Orthonormal decomposition of variance}

\section{Shoulder moment index (SMI)}

A

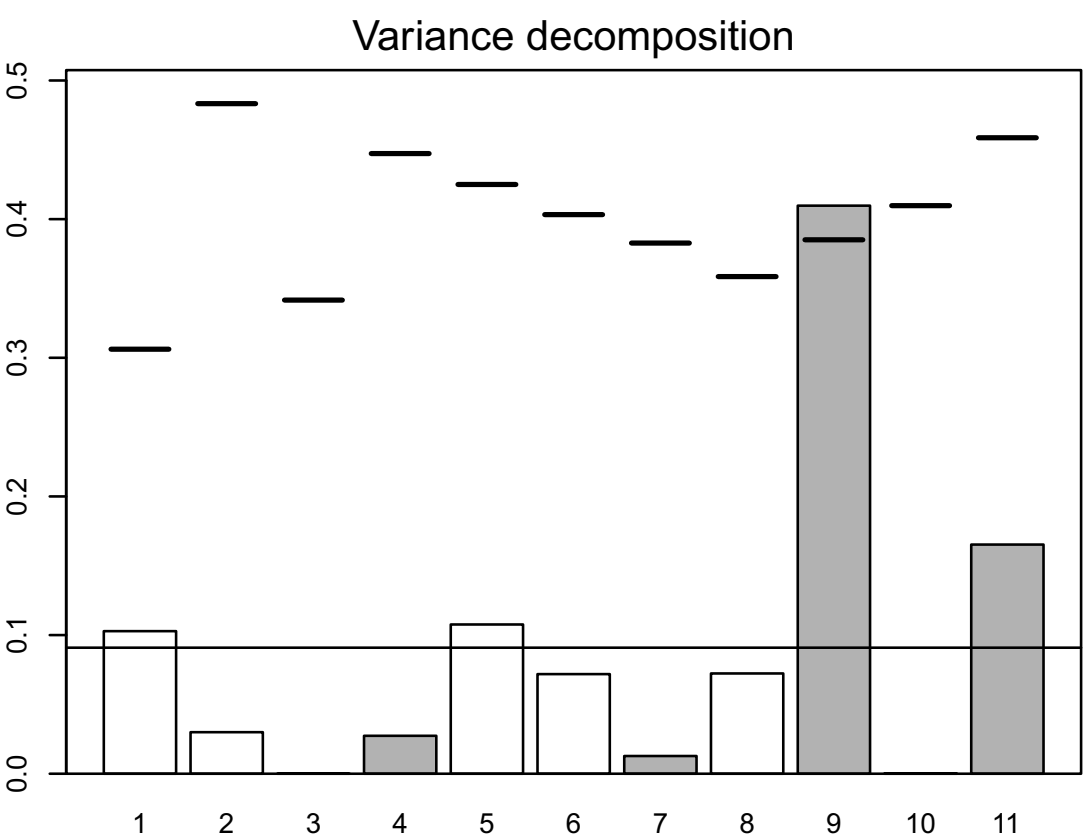

B

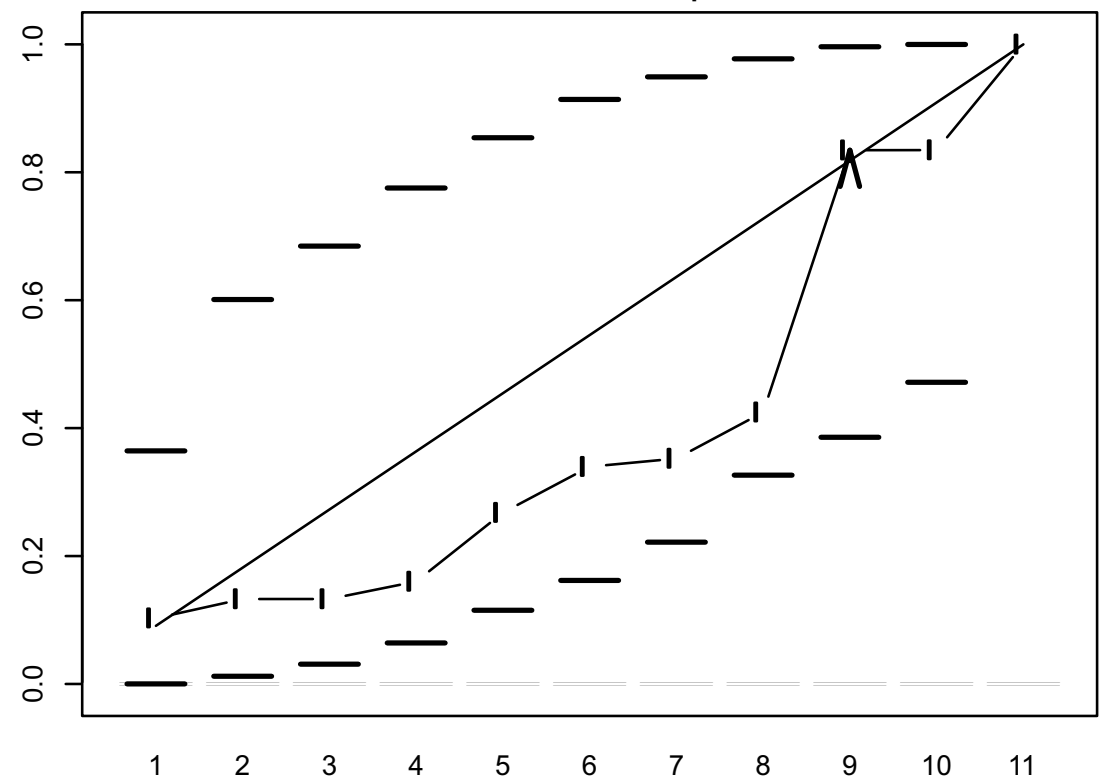

C

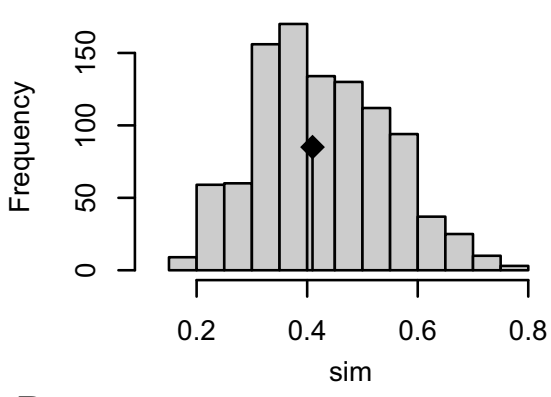

D SkR2k

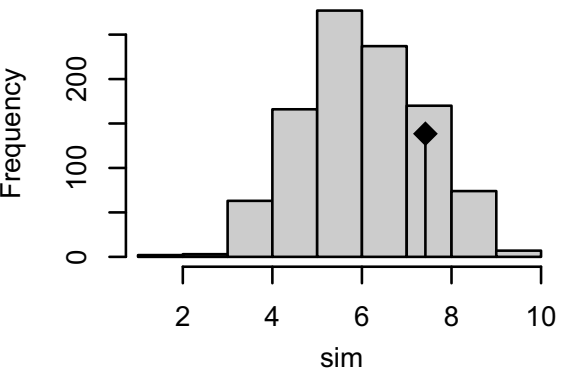

E

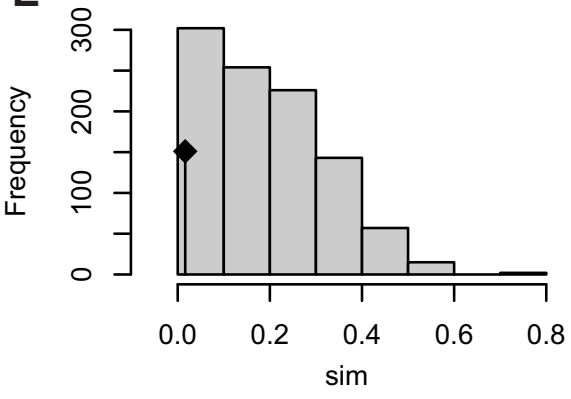

$\mathbf{F}$

SCE

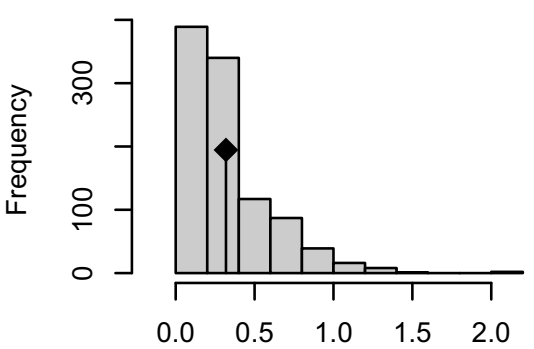

Figure S3.1. Orthonormal decomposition results from Shoulder Moment Index (SMI). A. Orthogram plot: bar height is proportional to the squared coefficients (white and grey bars represent positive and negative coefficients); dashed line is the upper confidence limit at $5 \%$, built from Monte Carlo permutations; horizontal solid line is the mean value; $\mathbf{B}$. Cumulative orthogram plot: circles represent observed values of cumulated squared coefficients (vertical axis); the expected values under $\mathrm{H}_{0}$ are displayed on the straight line; dashed lines represent the bilateral confidence interval; $\mathbf{C}-\mathbf{F}$. Histograms of observed values of the four statistic tests: black dot depicts the observed parameter value. 
The forelimbs of Octodontidae (Rodentia: Mammalia): substrate use, morphology and phylogenetical signal

M. Julieta Pérez*, Guillermo H. Cassini and M. Mónica Díaz

\section{Supplementary Material 3 - Orthonormal decomposition of variance}

\section{Humeral Robustness Index (HRI)}

A

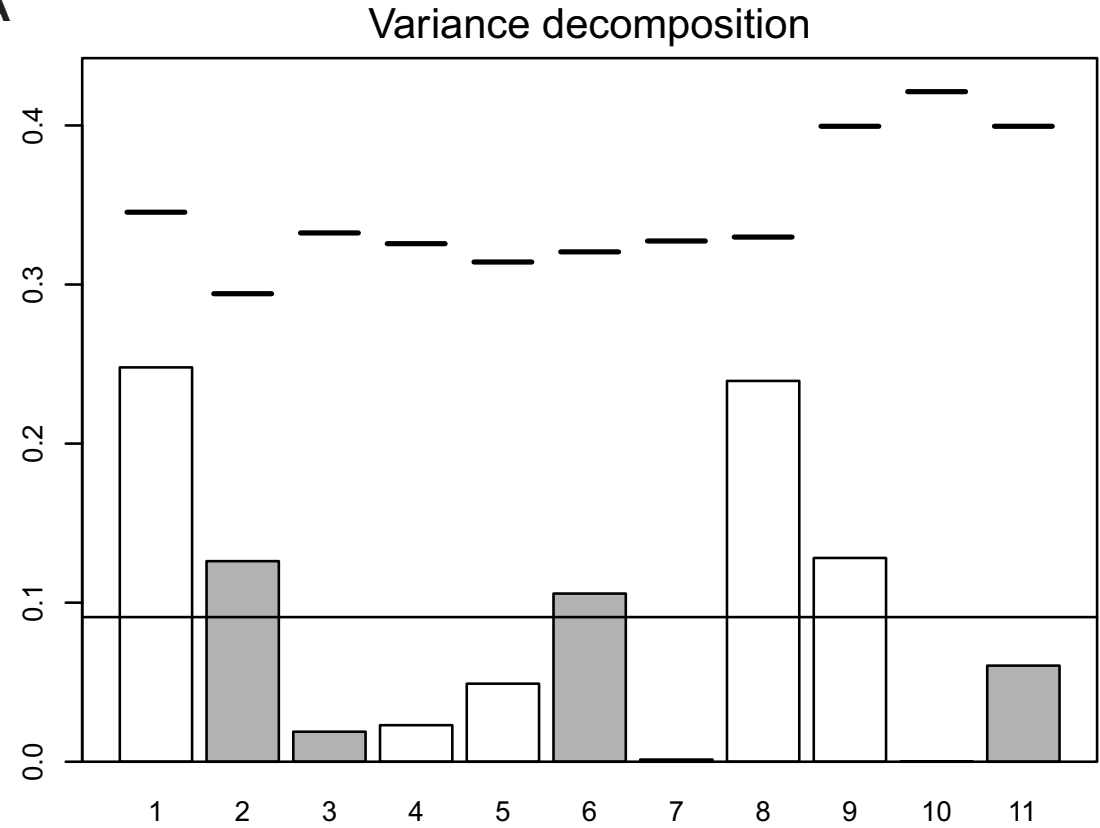

B

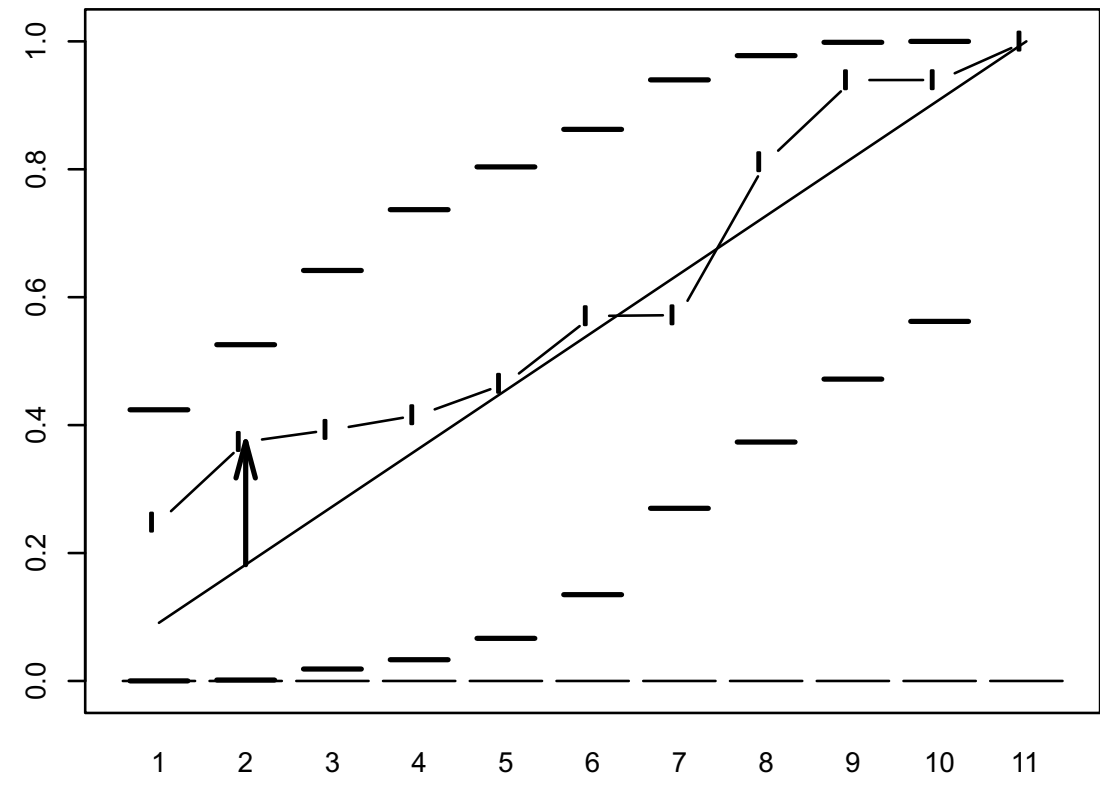

C

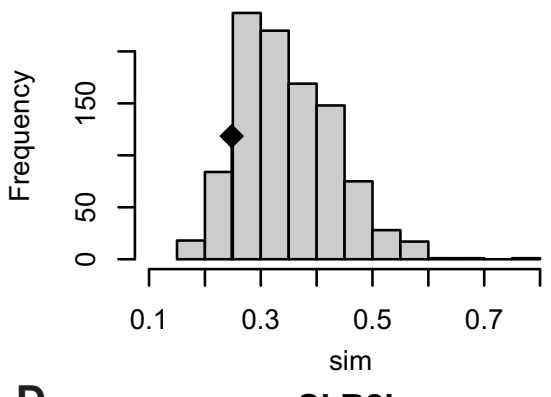

D SkR2k

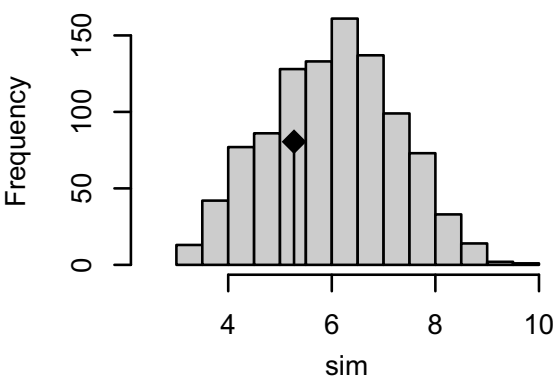

E

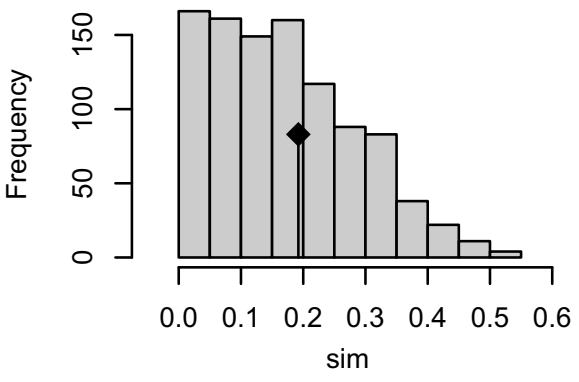

$\mathbf{F}$

SCE

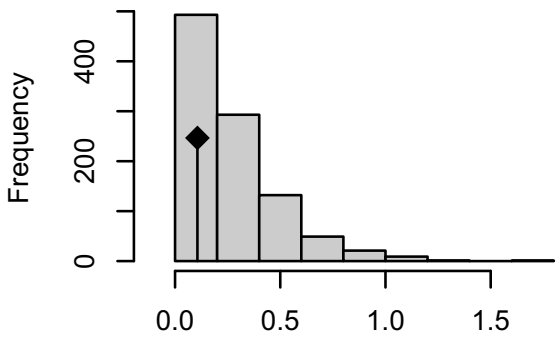

Figure S3.2. Orthonormal decomposition results from Humeral robustness index (HRI). A. Orthogram plot: bar height bar is proportional to the squared coefficients (white and grey bars represent positive and negative coefficients); dashed line is the upper confidence limit at $5 \%$, built from Monte Carlo permutations; horizontal solid line is the mean value; $\mathbf{B}$. Cumulative orthogram plot: circles represent observed values of cumulated squared coefficients (vertical axis); the expected values under $\mathrm{H}_{0}$ are displayed on the straight line; dashed lines represent the bilateral confidence interval; $\mathbf{C}-\mathbf{F}$. Histograms of observed values of the four statistic tests: black dot depicts the observed parameter value. 


\section{Epicondylar Index (EI)}

A

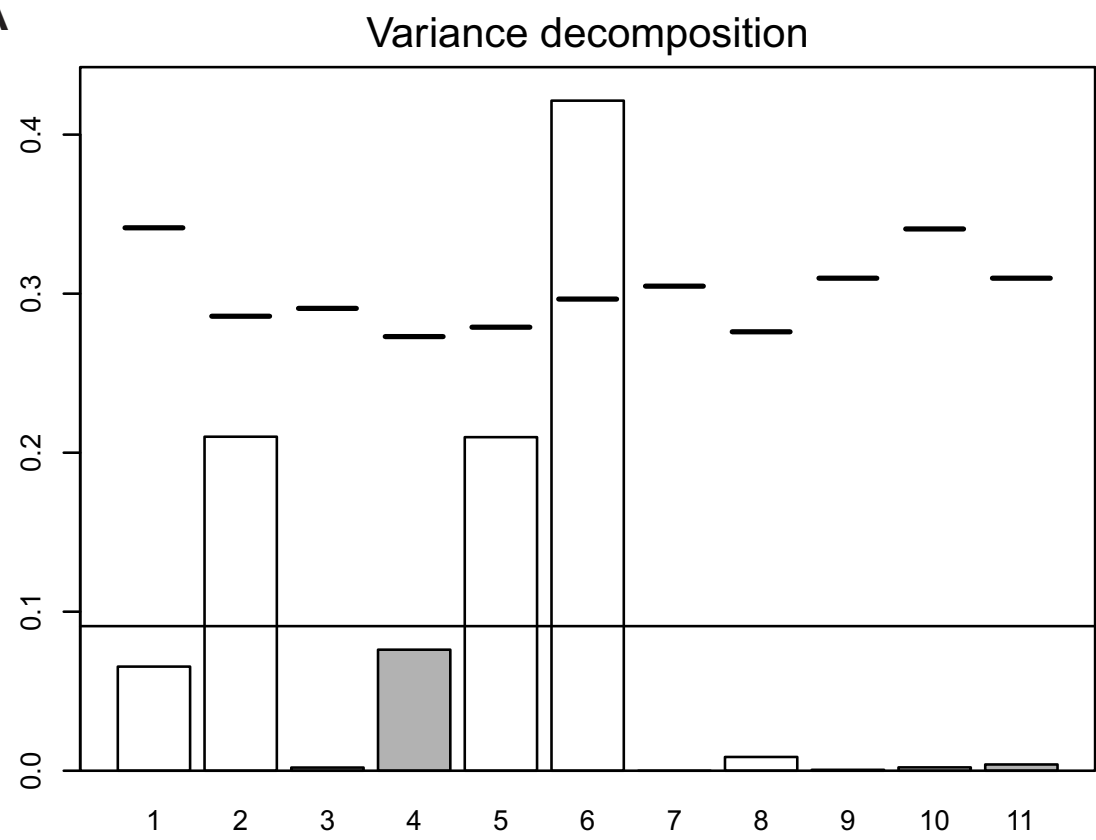

B

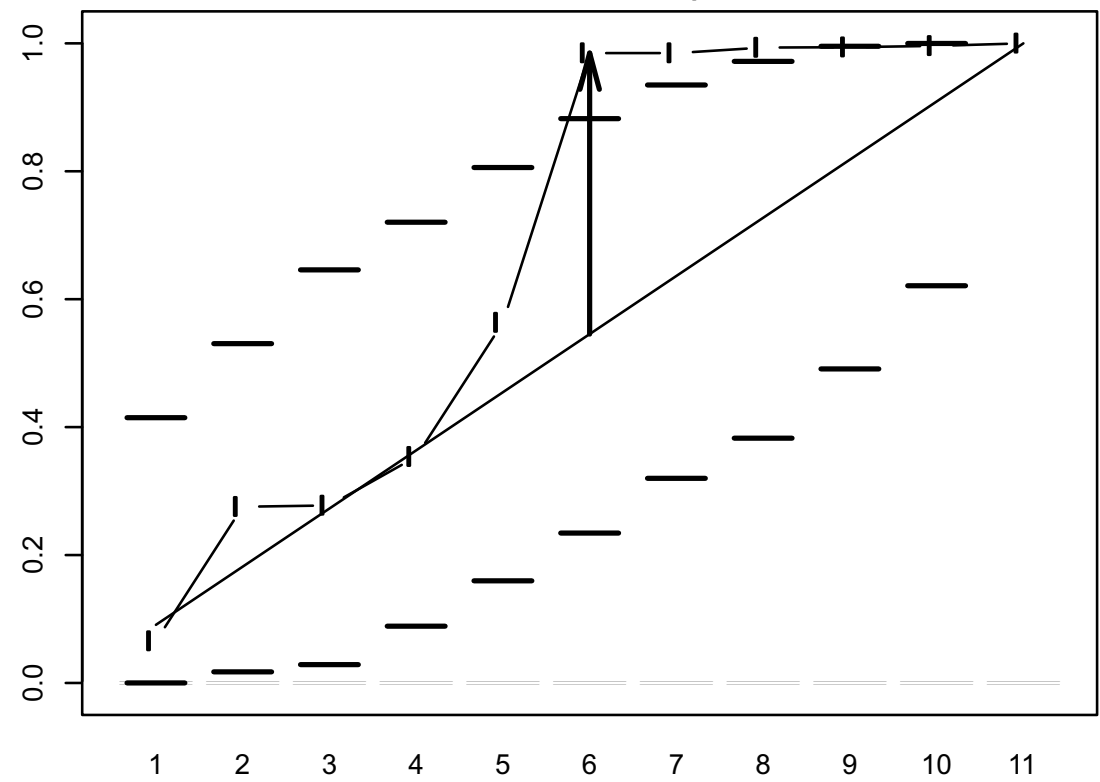

C

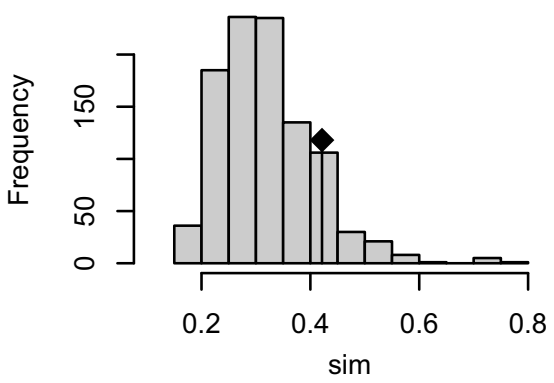

D

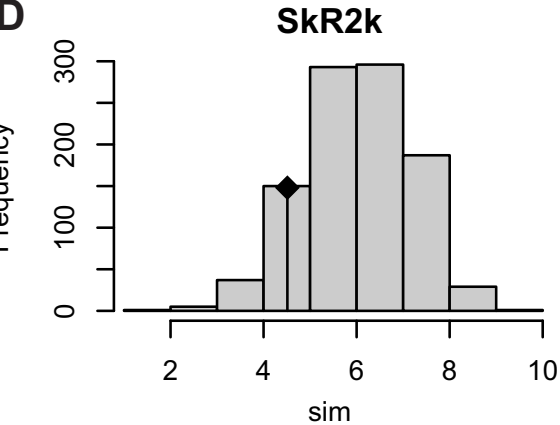

E

DMax
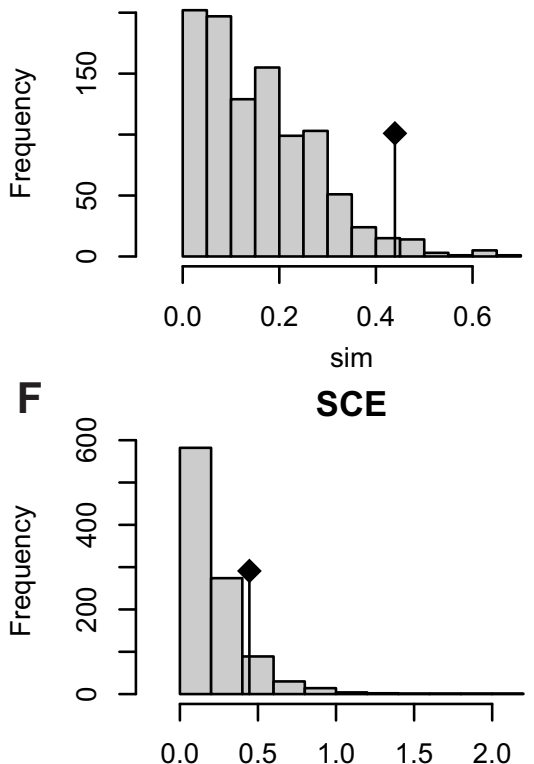

Figure S3.3. Orthonormal decomposition results from Epicondylar Index (EI). A. Orthogram plot: bar height is proportional to the squared coefficients (white and grey bars represent positive and negative coefficients); dashed line is the upper confidence limit at $5 \%$, built from Monte Carlo permutations; horizontal solid line is the mean value; $\mathbf{B}$. Cumulative orthogram plot: circles represent observed values of cumulated squared coefficients (vertical axis); the expected values under $\mathrm{H}_{0}$ are displayed on the straight line; dashed lines represent the bilateral confidence interval; $\mathbf{C}-\mathbf{F}$. Histograms of observed values of the four statistic tests: black dot depicts the observed parameter value. 
The forelimbs of Octodontidae (Rodentia: Mammalia): substrate use, morphology and phylogenetical signal

M. Julieta Pérez*, Guillermo H. Cassini and M. Mónica Díaz

\section{Supplementary Material 3 - Orthonormal decomposition of variance}

\section{Ulnar Robustness Index (URI)}

A

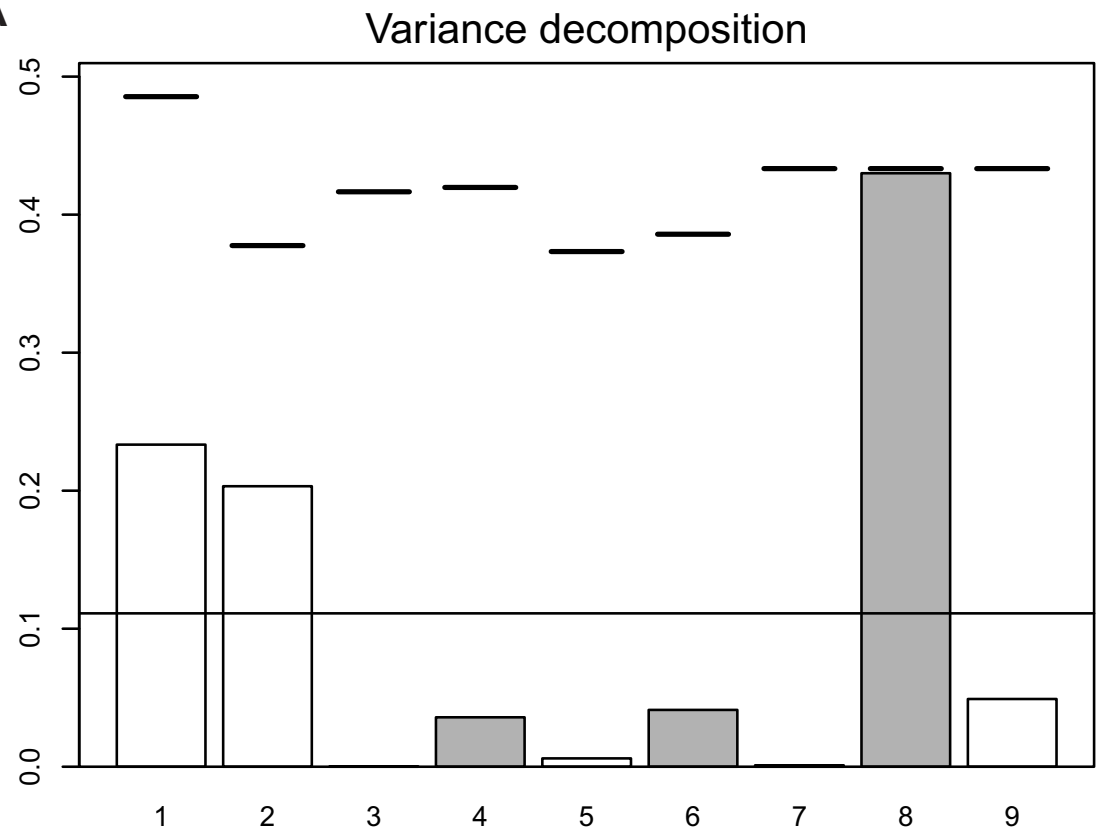

B

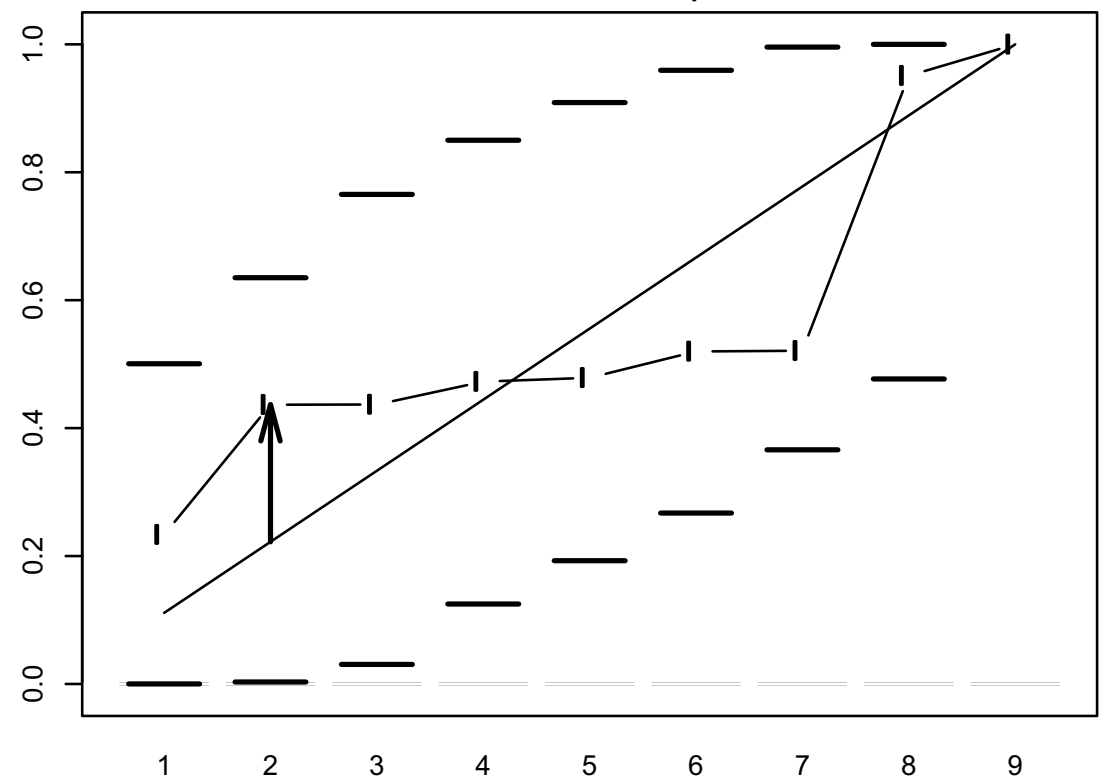

C

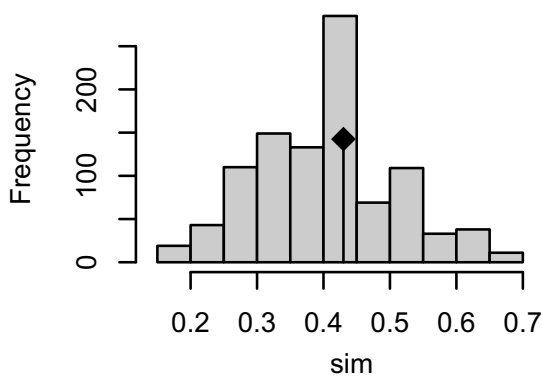

D SkR2k

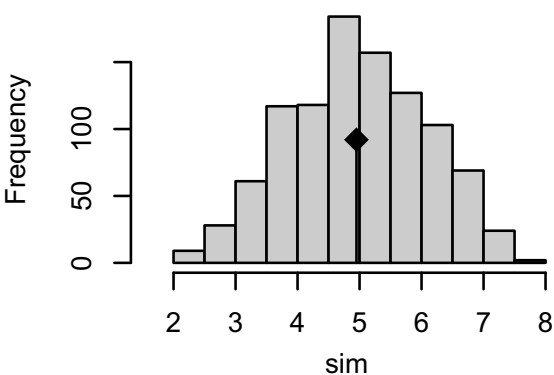

E

DMax

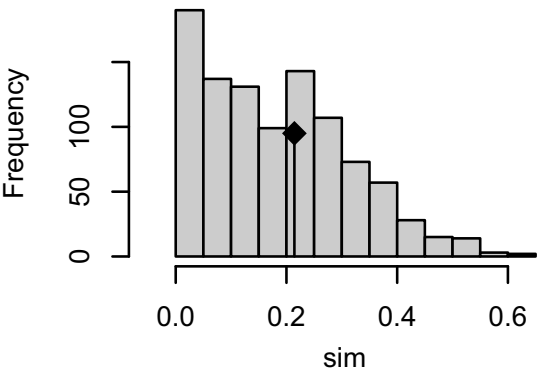

$\mathbf{F}$

SCE

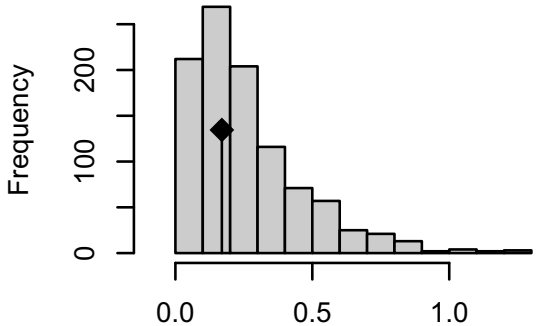

Figure S3.4. Orthonormal decomposition results from Ulnar Robustness Index (URI). A. Orthogram plot: bar height is proportional to the squared coefficients (white and grey bars represent positive and negative coefficients); dashed line is the upper confidence limit at $5 \%$, built from Monte Carlo permutations; horizontal solid line is the mean value; $\mathbf{B}$. Cumulative orthogram plot: circles represent observed values of cumulated squared coefficients (vertical axis); the expected values under $\mathrm{H}_{0}$ are displayed on the straight line; dashed lines represent the bilateral confidence interval; $\mathbf{C}-\mathbf{F}$. Histograms of observed values of the four statistic tests: black dot depicts the observed parameter value. 
The forelimbs of Octodontidae (Rodentia: Mammalia): substrate use, morphology and phylogenetical signal

M. Julieta Pérez*, Guillermo H. Cassini and M. Mónica Díaz

\section{Supplementary Material 3 - Orthonormal decomposition of variance}

\section{Olecranon Index (OI)}

A

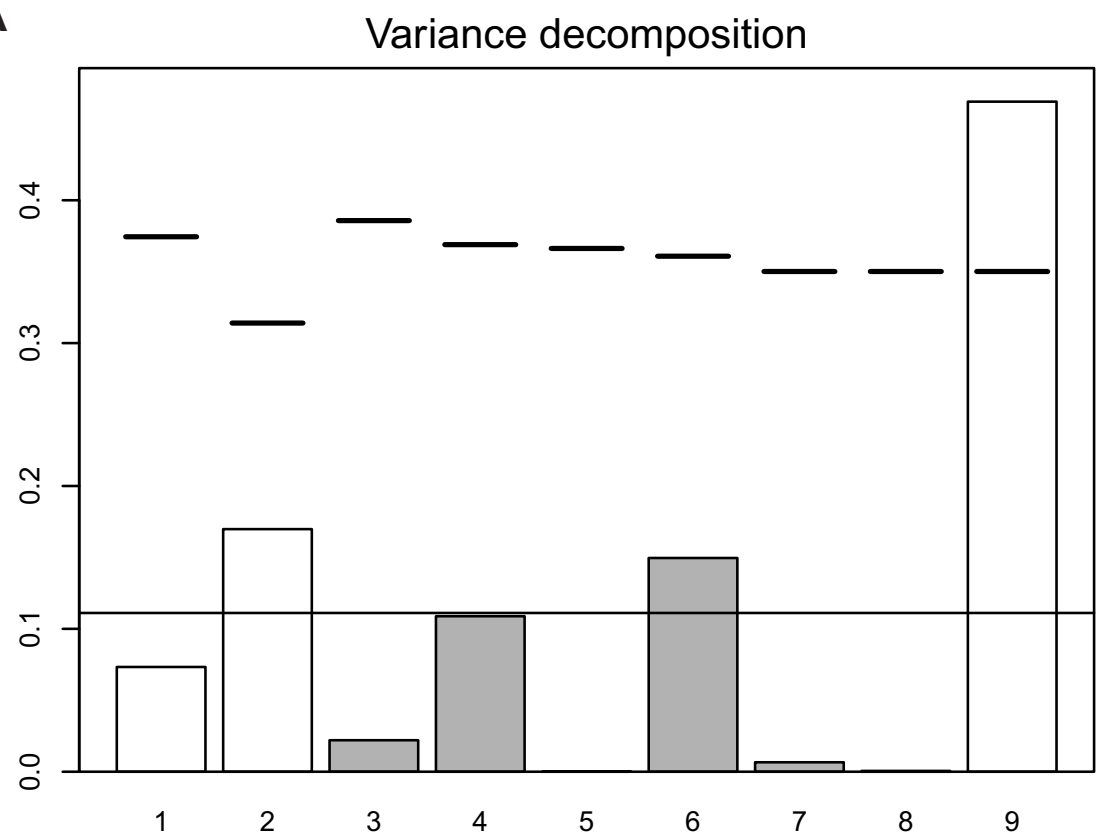

B

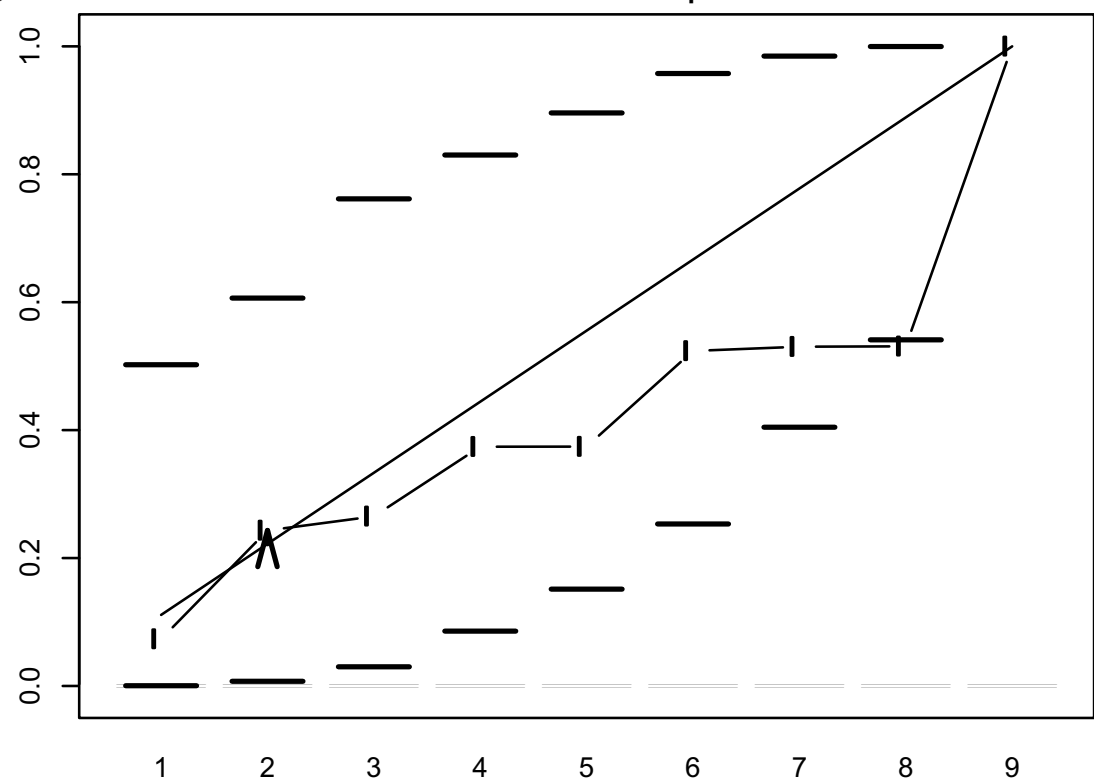

C

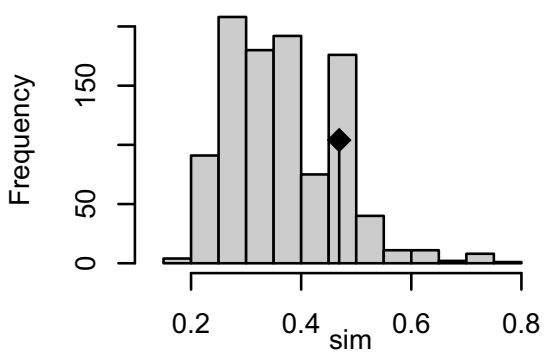

D SkR2k

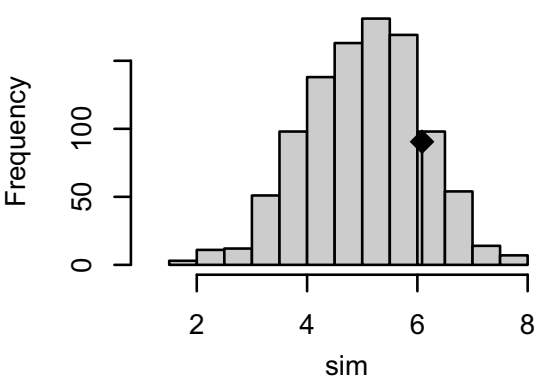

E

DMax

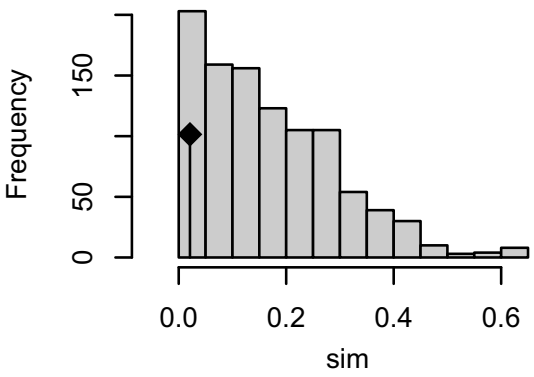

$\mathbf{F}$

SCE

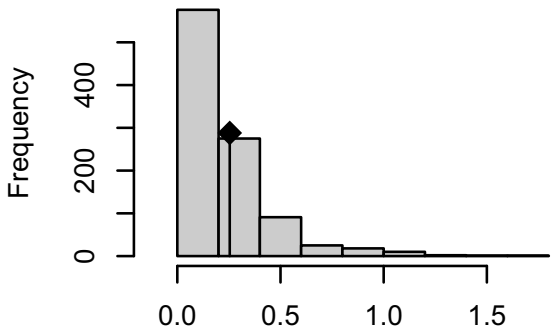

Figure S3.5. Orthonormal decomposition results from Olecranon Index $(\mathrm{OI})$. A. Orthogram plot: bar height is proportional to the squared coefficients (white and grey bars represent positive and negative coefficients); dashed line is the upper confidence limit at $5 \%$, built from Monte Carlo permutations; horizontal solid line is the mean value; $\mathbf{B}$. Cumulative orthogram plot: circles represent observed values of cumulated squared coefficients (vertical axis); the expected values under $\mathrm{H}_{0}$ are displayed on the straight line; dashed lines represent the bilateral confidence interval; $\mathbf{C}-\mathbf{F}$. Histograms of observed values of the four statistic tests: black dot depicts the observed parameter value. 
The forelimbs of Octodontidae (Rodentia: Mammalia): substrate use, morphology and phylogenetical signal

M. Julieta Pérez*, Guillermo H. Cassini and M. Mónica Díaz

\section{Supplementary Material 4 - phylogenetic Flexible Discriminant Analysis}

\section{Results}

The phylogenetic Flexible Discriminant Analysis (pFDA) performed in the whole sample with three biomechanical indices (SMI, HRI and EI), the estimated optimal Pagel's lamnda was 0 (i.e., indicate no phylogenetic signal), and the confusion matrix has showed no misclassification cases. Next step was evaluating the reclassification of each species at increasing lambda values, and appeared some misclassifications. Among fossorials, Octodon degus was misclassified as semifossorial from lambda 0.4 to 1 ; and Aconaemys fuscus and O. bridgesi from 0.9. Among semifossorials Tympanoctomys aureus was misclassified as epigean at lambda 0.2 to 0.5 and as fossorial from 0.6 to 1 , while Tympanoctomys barrerae was reclassified as fossorial at lambda 0.9 (Fig. S.4.1).

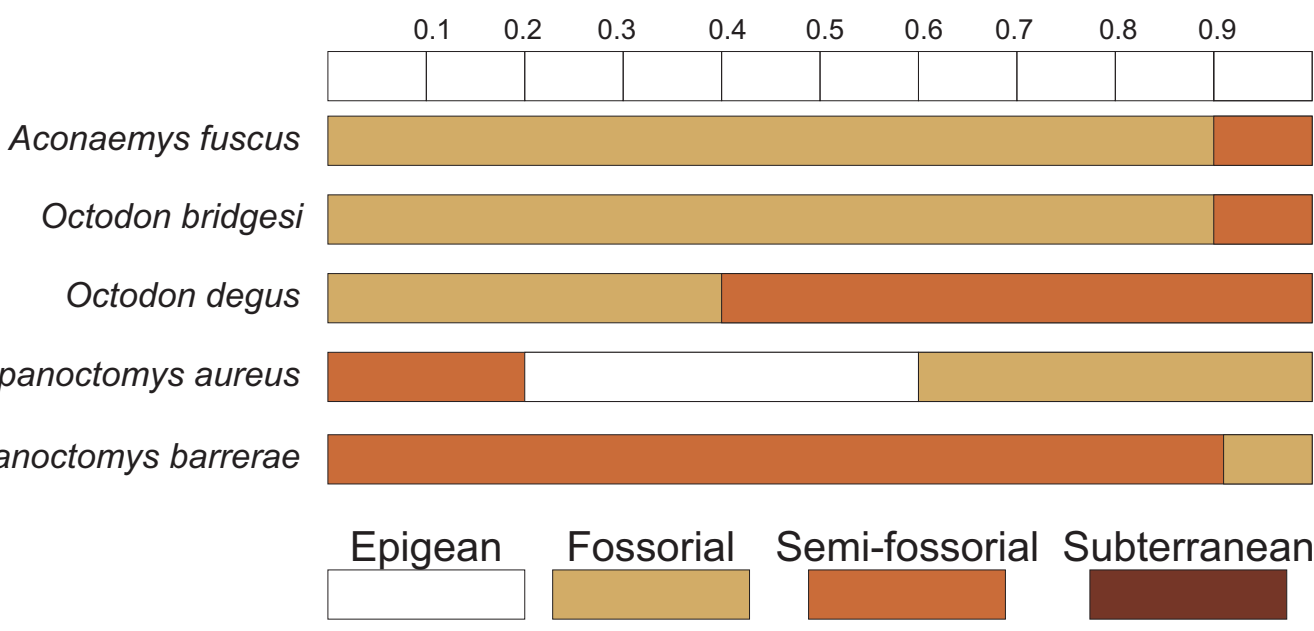

Figure S4.1. Missclassifications of octodontids on the basis of phylogenetic flexible discriminant analysis. The upper bar indicates the variation in Page's lambda values and colored boxes indicates the results in different substrate preference categories classifications.

\section{Discussion}

The present analysis shows that the optimal Pagel's lambda of cero corresponds to an absence of phylogenetic signal. It could be argued that the formfunction system of these three biomechanical indices (SMI, HRI and EI), evolved independently of phylogenetic structure and close relatives are not more similar than distant relatives.

It is noteworthy that from the five species that were misclassified, three of them do it at high Pagel's lambda (0.9) which assumes a high phylogenetic signal. However, the assigned category was a close one (fossorial as semifossorial and viceversa), which suggests that our categories represent subdivisions of a continuous spectrum of substrate preference or faculties

\section{References}

Cassini, G.H., Cerdeno, M.E., Villafane, A.L. and Munoz, N.A. 2012. Paleobiology of Santacrucian native ungulates (Meridiungulata: Astrapotheria, Litopterna and Notoungulata). In: S.F. Vizcaino, R. Kay and M.S. Bargo (Eds.), Early Miocene paleobiology in Patagonia: high-latitude paleocommunities of the Santa Cruz Formation. Cambridge University Press, Cambridge, p. 243-286.

Elissamburu, A., Vizcaíno, S. F., 2004. Limb proportions and adaptations in caviomorph rodents (Rodentia: Caviomorpha). J. Zool. 262:145-159.

Toledo, N., Bargo, M. S., Cassini, G. H., Vizcaíno, S. F., 2012. The forelimb of early Miocene sloths (Mammalia, Xenarthra, Folivora): morphometrics and (e.g., digging) which in turn can be aligned with different biological roles (to forage, build shelters, etc; see Vizcaíno et al. (2016)).

Additionally, it should be considered that in order to include all the species sampled, the three indices analyzed involve only measures from the humerus bone. Several authors highlight the functional and/or biomechanical correlation of these three indices to scratch-digging behavior (Elissamburu and Vizcaíno, 2004; Cassini et al., 2012; Toledo et al., 2012). However, the ulna has been proposed as one of the forelimb elements bearing clear specializations for scratch or digging behavior (see Toledo et al., 2020; Vizcaíno and Bargo, 2019).

functional implications for substrate preferences. J. Mamm. Evol. 19:185-198.

Toledo, N., Muñoz, N. A., Cassini, G. H., 2020. Ulna of Extant Xenarthrans: Shape, Size, and Function. J. Mamm. Evol. doi.org/10.1007/s10914-020-09503-y.

Vizcaíno, S. F., Bargo, M. S., 2019. Views on the form-function correlation and biological design. J. Mamm. Evol.doi.org/10.1007/s10914-019-09487-4.

Vizcaíno, S. F., Bargo, M. S., Cassini, G. H., Toledo, N., 2016. Forma y Función en Paleobiología de Vertebrados. Editorial de la Universidad Nacional de La Plata (EDULP), La Plata. 


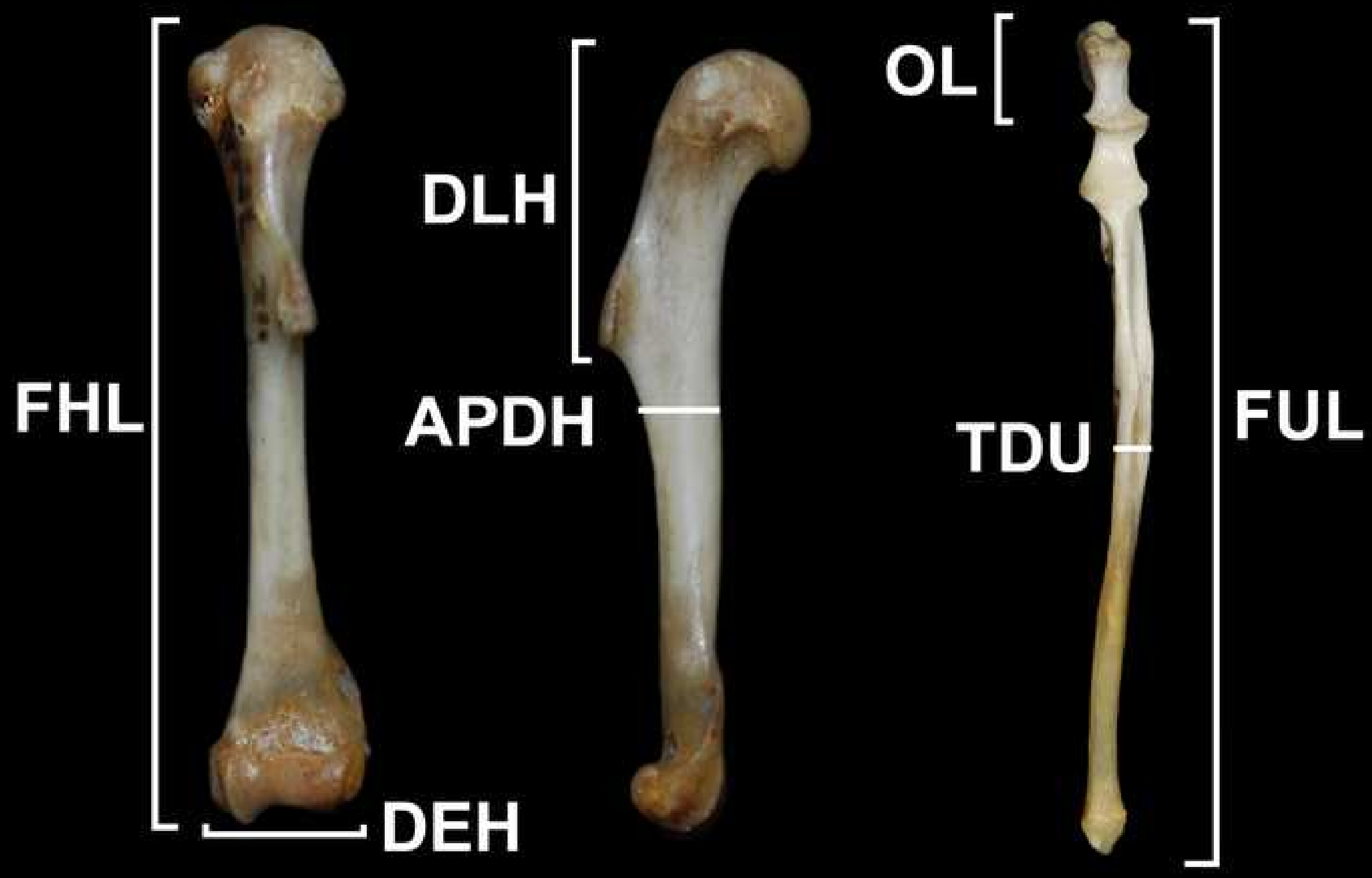



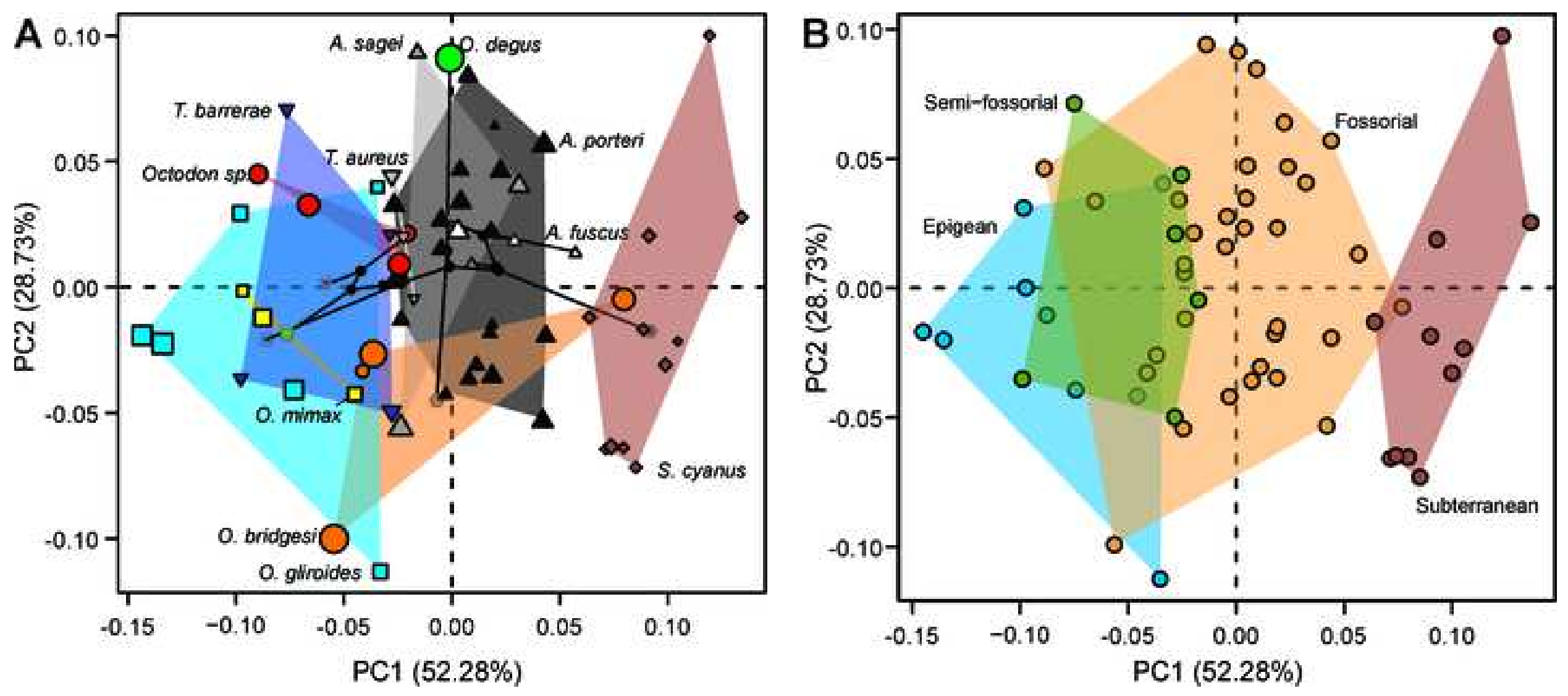


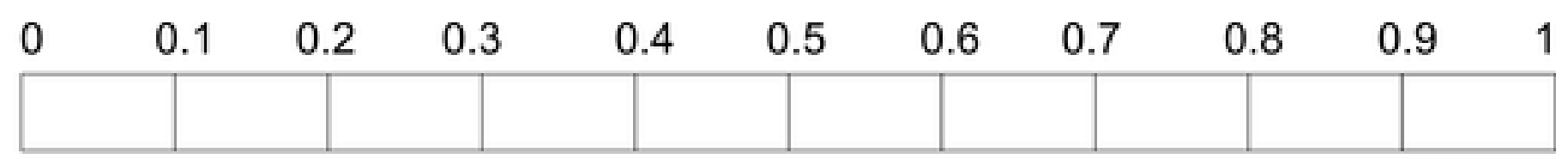

Aconaemys fuscus

Octodon bridgesi

Octodon degus

Tympanoctomys aureus

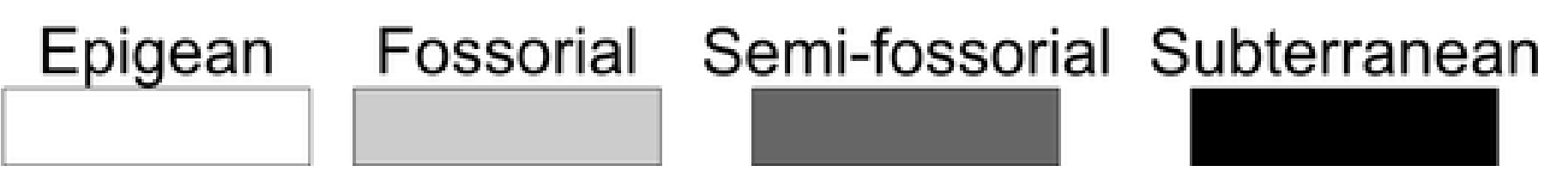




\section{A}

B

C
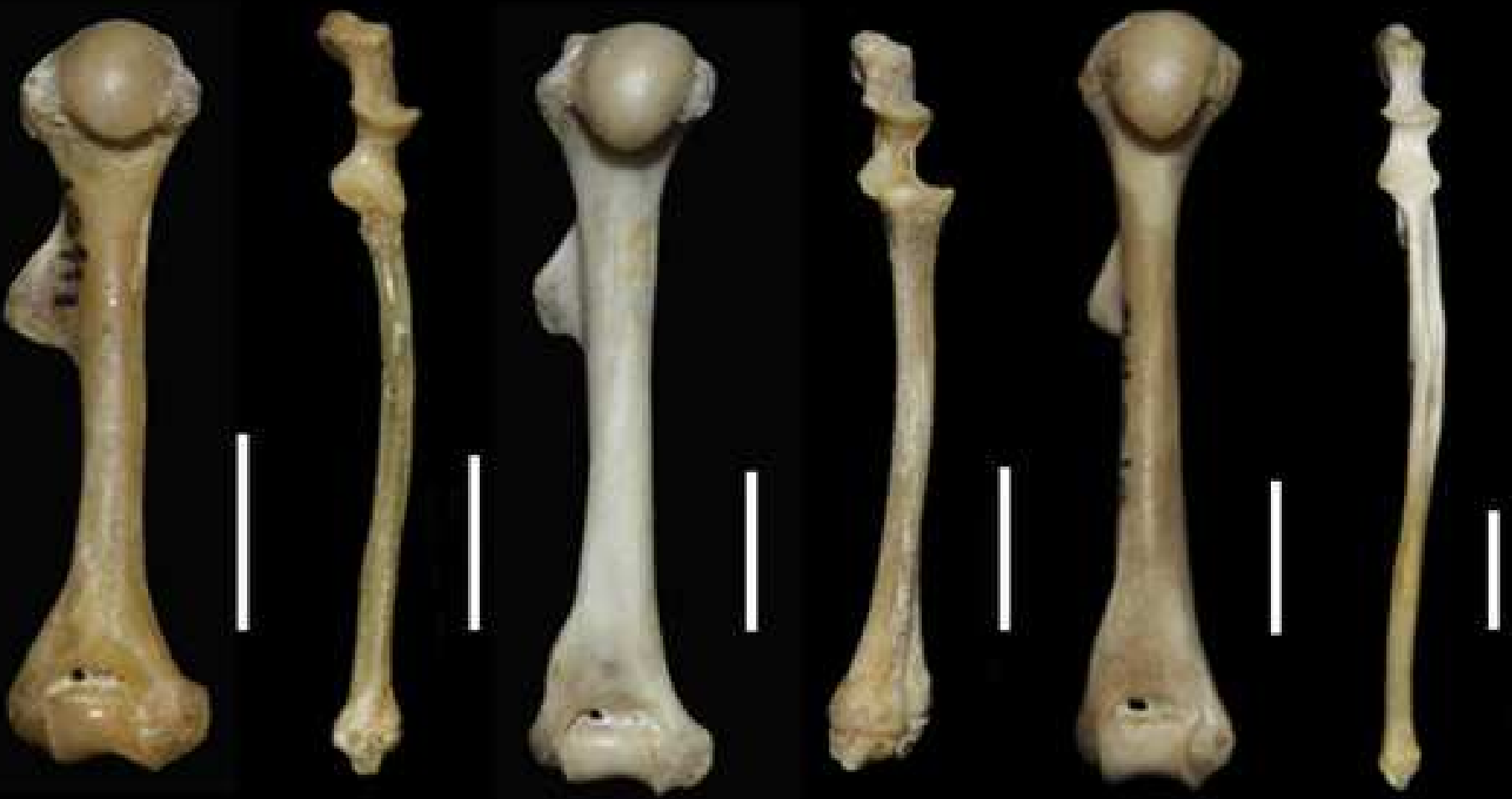

D

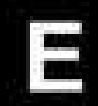

F
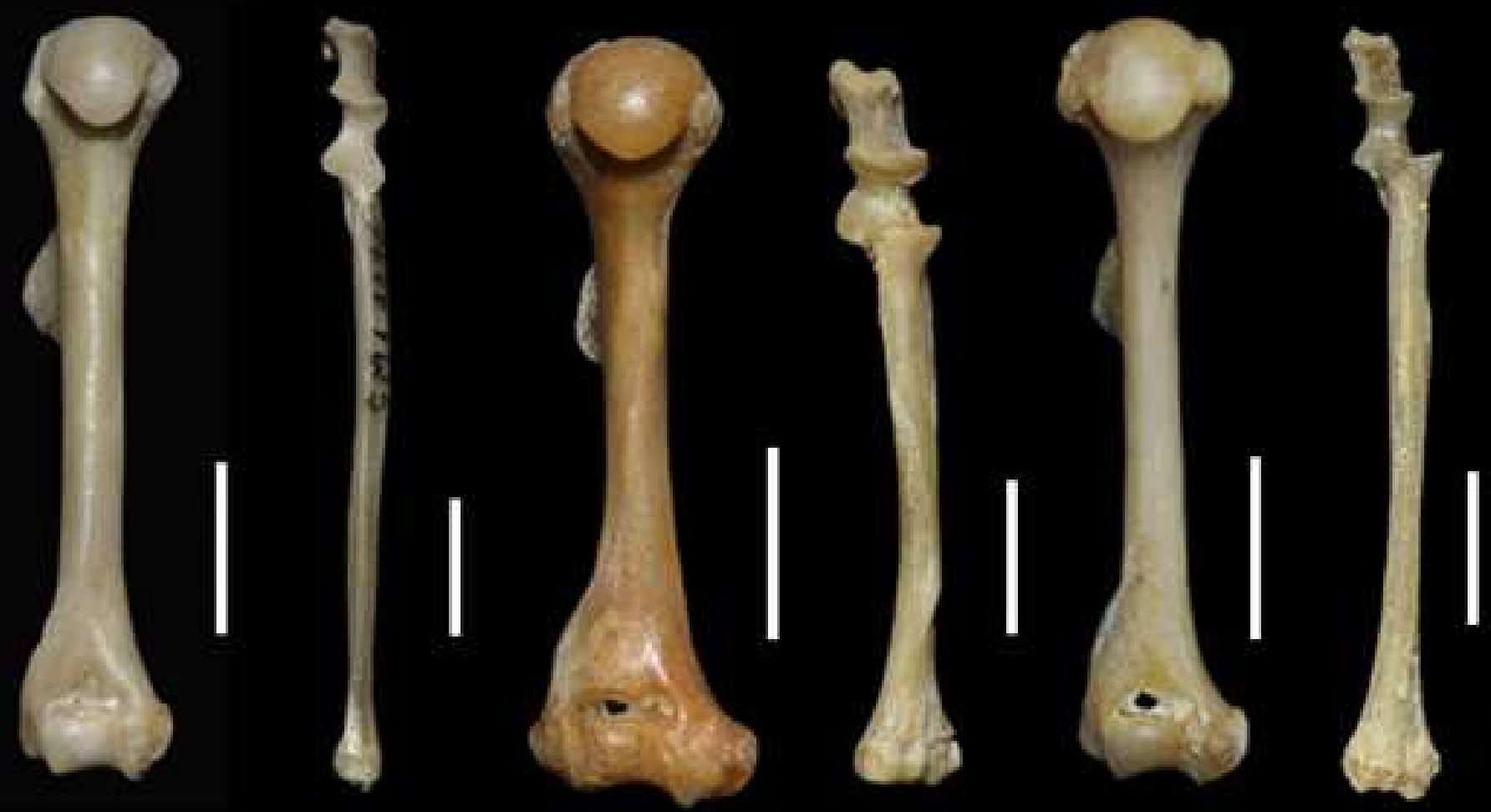